\title{
Deregulation of purine metabolism in Alzheimer's disease
}

\author{
Belén Ansoleaga ${ }^{\mathrm{a}, 1}$, Mariona Jové ${ }^{\mathrm{b}, 1}$, Agatha Schlüter ${ }^{\mathrm{c}}$, Paula Garcia-Esparcia ${ }^{\mathrm{a}}$, \\ Jesús Moreno a, Aurora Pujol ${ }^{\mathrm{c}, \mathrm{d}, \mathrm{e}}$, Reinald Pamplona ${ }^{\mathrm{b}}$, Manuel Portero-Otín ${ }^{\mathrm{b}}$, \\ Isidre Ferrer ${ }^{\mathrm{a}, \mathrm{f}, \mathrm{g}, *}$ \\ a Institute of Neuropathology, Bellvitge University Hospital-Bellvitge Biomedical Research Institute (IDIBELL), L'Hospitalet de Llobregat, Spain \\ ${ }^{\mathrm{b}}$ Department of Experimental Medicine, University of Lleida-Biomedical Research Institute of Lleida, Lleida, Spain \\ ${ }^{\mathrm{c}}$ Neurometabolic Diseases Laboratory, IDIBELL, L'Hospitalet de Llobregat, Spain \\ ${ }^{\mathrm{d}}$ Centre for Biomedical Research on Rare Diseases (CIBERER), Institute Carlos III, Madrid, Spain \\ e Catalan Institution for Research and Advanced Studies (ICREA), Barcelona, Spain \\ ${ }^{\mathrm{f}}$ University of Barcelona, Bellvitge Campus, L'Hospitalet de Llobregat, Spain \\ ${ }^{g}$ Centre for Networked Biomedical Research in Neurodegenerative Diseases (CIBERNED), Institute Carlos III, Madrid, Spain
}

\section{A R T I C L E I N F O}

\section{Article history:}

Received 28 March 2014

Accepted 5 August 2014

\section{Keywords:}

Alzheimer's disease

Frontal cortex

Entorhinal cortex

Precuneus

Purine metabolism

Metabolomics

Mass spectrometry

\begin{abstract}
A B S T R A C T
The neuroprotective role of adenosine and the deregulation of adenosine receptors in Alzheimer's disease (AD) have been extensively studied in recent years. However, little is known about the involvement of purine metabolism in $\mathrm{AD}$. We started by analyzing gene expression in the entorhinal cortex of human controls and $\mathrm{AD}$ cases with whole-transcript expression arrays. Once we identified deregulation of the cluster purine metabolism, messenger RNA expression levels of 23 purine metabolism genes were analyzed with qRT-PCR in the entorhinal cortex, frontal cortex area 8, and precuneus at stages I-II, III-IV, and V-VI of Braak and Braak and controls. APRT, DGUOK, POLR3B, ENTPD3, AK5, NME1, NME3, NME5, NME7, and ENTPD2 messenger RNAs were deregulated, with regional variations, in AD cases when compared with controls. In addition, liquid chromatography mass spectrometry based metabolomics in the entorhinal cortex identified altered levels of dGMP, glycine, xanthosine, inosine diphosphate, guanine, and deoxyguanosine, all implicated in this pathway. Our results indicate stage- and regiondependent deregulation of purine metabolism in AD.
\end{abstract}

(c) 2014 Elsevier Inc. All rights reserved.

\section{Introduction}

Alzheimer's disease (AD) is a human age-related biological process which causes progressive degeneration of the brain and which is characterized clinically by cognitive impairment and dementia, and neuropathologically by the variable combination of 2 hallmarks, neurofibrillary tangles composed of abnormally phosphorylated, and conformed and truncated tau, and senile plaques with a core of the altered cleavage of amyloid precursor protein leading to the deposition of $\beta$-amyloid (Duyckaerts and Dickson, 2011; Haass and Selkoe, 2007; Lowe et al., 2008). In addition to the pathologic hallmarks of $A D$, several other abnormalities have been reported in $A D$, including mitochondrial malfunction; increased oxidative stress and oxidative/ nitrosative damage to nucleic acids, proteins, and lipids; energy metabolism failure; altered composition of lipids in lipid rafts;

\footnotetext{
* Corresponding authors at: Institute of Neuropathology, Service of Pathology, Bellvitge University Hospital, Carrer Feixa Llarga sn, 08907 Hospitalet de Llobregat, Spain. Tel.: +34 93 2607452; fax: +34 932607503.

E-mail address: 8082ifa@gmail.com (I. Ferrer).

${ }^{1}$ Both the authors contributed equally to this work.
}

neuroinflammation; and endoplasmic reticulum stress, impaired ubiquitin-proteasome system, and autophagy (Ferrer, 2012). Multiple signaling and neurotransmitter pathways are altered compromising neuron-neuron interactions and glial-neurons interactions.

Purines are heterocyclic double-ring aromatic organic molecules; primary purine adenine and guanosine nucleobases, together with one-ring primary pyrimidine nucleobases cytosine, thymidine, and uracil, are the core of DNA, RNA, nucleosides, and nucleotides. Adenosine and guanosine are purine ribonucleosides resulting from the $\beta$-N9-glycosidic bound to adenine or guanine and ribose, respectively. When adenine and guanine are attached to the $\mathrm{C} 1 \mathrm{car}-$ bon of a deoxyribose ring, the resulting compounds are deoxyadenosine and deoxyguanosine, respectively. Nucleotides result from the incorporation of phosphate groups in nucleosides: Adenosine monophosphate (AMP), adenosine diphosphate, Adenosine triphosphate (ATP), guanosine monophosphate, guanosine diphosphate, guanosine triphosphate, and cyclic forms cAMP and cGMP are primary purine-derived nucleotides. Modified purine nucleobases hypoxantine and xanthine result from the replacement of the aminogroup by a carbonyl-group from adenine and guanine, respectively, whereas methyl-guanine results from the incorporation of a methyl 
group to guanine. Corresponding modified purine nucleosides are inosine, xanthosine, and methyl-guanosine, respectively. Nucleotides participate in a wide variety of crucial metabolic pathways including energy metabolism and cell signaling. In addition, purine bases are incorporated to other molecules to form cofactors of several enzymatic reactions such as coenzyme $A$, flavin adenine dinucleotide (FAD), nicotinamide adenine dinucleotide (NAD+), nicotinamide adenine dinucleotide phosphate (NADP+), and the corresponding reduced forms FADH2, NADH, and NADPH. S-Adenosyl methionine is made from ATP and methionine by methionine adenosyltransferase and is involved in the transfer of methyl groups to distinct substrates, including nucleic acids, proteins, lipids, and metabolites. In addition to intracellular signaling, purines and their products may function as extracellular signals acting on other cells, either between neurons or neurons and glial cells equipped with appropriate receptors (Ipata et al., 2011). Adenosine is responsible for regulating, integrating and fine-tuning neuronal activity, and influencing relevant brain functions, including sleep and arousal, cognition and memory, and neuronal damage and degeneration, by acting as an extracellular molecular via specific adenosine receptors (Rahman, 2009). Adenosine receptor signaling also modulates permeability of the bloodbrain barrier (Carman et al., 2011). Adenosine exerts its function by binding adenosine receptors which are G-protein-coupled receptors (A1, A2A, A2B, and A3) that can inhibit (A1 and A3) or enhance (A2) neuronal communication through neurotransmitter release (Ribeiro et al., 2003). Several indirect data suggest altered purine metabolism in AD. Energy metabolism dependent on mitochondrial function and ATP production is markedly altered in $\mathrm{AD}$ (Ferreira et al., 2010; Ferrer, 2009). In addition, oxidative damage to DNA and RNA, as revealed by the increase in 8-hydroxyguanosine, is found in the brain in AD (Lovell and Markesbery, 2008; Lovell at al., 2011; Markesbery and Lovell, 2006; Nonumura et al., 2012; Weidner et al., 2011). Regarding purine neurocrine factors, adenosine receptors have attracted interest because of the neuroprotective effects of adenosine in several neurologic disorders (Boisson, 2008; Ribeiro et al., 2003). Experiments carried out with cell lines have demonstrated that A1 activation mediates the production of soluble forms of $\beta$-amyloid and tau phosphorylation (Angulo et al., 2003). Furthermore, blockade of A2A receptors in rat cultured cerebellar granule neurons with $A \beta 25-$ 35 prevents $\beta$-amyloid-induced neurotoxicity (Dall'Igna et al., 2003), suggesting that the presence of $A 2 A$ is critical for $A \beta$ toxicity (Rahman, 2009). cAMP is an endogenous modulator of the $\beta$-amyloid precursor protein metabolism (Canepa et al., 2013). Decreased levels of A1 receptors and altered binding of adenosine agonists and antagonists to A1 receptors have been observed in the molecular layer of the CA1 region of the hippocampus in AD (Ulas et al., 1993). In contrast, upregulation of $A 1$ and $A 2 A$ receptors has been reported in the frontal cortex in AD (Albasanz et al., 2008).

Direct alterations of purine metabolism in AD have also been detected by metabolomics in the ventricular cerebrospinal fluid at postmortem (Kaddurah-Daouk et al., 2011) and in the cerebrospinal fluid in living individuals (Isobe et al., 2010; Kaddurah-Daouk et al., 2013; Jové et al., 2014). Only a limited number of metabolomic studies have been carried out in AD brains (Jové et al., 2014).

However, little is known about possible alterations in the expression of genes encoding enzymes involved in purine metabolism in AD brains. This information would permit a better understanding of the primary regulation of purine-related genes and their possible implications in the pathogenesis of the disease. First, functional genomics in a short series of $\mathrm{AD}$ cases revealed a deregulated cluster of genes involved in purine metabolism in the entorhinal cortex in AD brains. Second, the expression of selected genes was analyzed in the enthorinal cortex, frontal cortex area 8 , and precunneus at stages I-II, III-IV, and V-VI of Braak and Braak, compared with controls. Finally, metabolomics was applied to the study of the entorhinal cortex to increase the understanding of functional implications of deregulated purine metabolism. We fully understand that the postmortem study of the human brain has certain limitations because it cannot be manipulated premortem, and because it is subject to degradation processes. Nevertheless, the study of the human postmortem brain cannot be replaced by any model, and it represents an invaluable source of knowledge.

\section{Methods}

\subsection{Human cases}

Brain tissue was obtained from the Institute of Neuropathology HUB-ICO-IDIBELL Biobank following the guidelines of Spanish legislation on this matter and the approval of the local ethics committee. The postmortem interval between death and tissue processing was between 3 and 20 hours. One hemisphere was immediately cut in coronal sections, $1-\mathrm{cm}$ thick, and selected areas of the encephalon were rapidly dissected, frozen on metal plates over dry ice, placed in individual air-tight plastic bags, numbered with water-resistant ink, and stored at $-80{ }^{\circ} \mathrm{C}$ until use for biochemical studies. The other hemisphere was fixed by immersion in $4 \%$ buffered formalin for 3 weeks for morphologic studies. Neuropathologic study in all cases was routinely performed on 20 dewaxed paraffin sections comprising different regions of the cerebral cortex, diencephalon, thalamus, brain stem, and cerebellum, which were stained with hematoxylin and eosin, Klüver-Barrera, and for immunohistochemistry to microglia, glial fibrillary acidic protein, $\beta$-amyloid, phosphorylated tau (clone AT8), $\alpha$-synuclein, TDP-43, ubiquitin, and p62.

Neuropathologic diagnosis of $A D$ was based on the classification of Braak and Braak (Braak and Braak, 1991, 1999) adapted to paraffin sections (Braak et al., 2006).

Cases with combined pathologies (i.e., Parkinson's disease, tauopathy, vascular diseases, and metabolic syndrome) were excluded from the present study. Age-matched control cases had not suffered from neurologic or psychiatric diseases, or metabolic diseases (including metabolic syndrome), and did not have abnormalities in the neuropathologic examination (excepting Braak and Braak stages I-II).

Cases used in the present study for messenger RNA (mRNA) expression corresponded to $23 \mathrm{AD}$ stages III-IV (12 men, 11 women), 35 AD stages V-VI ( 20 men, 15 women), and 34 controls ( 21 men, 13 women). Three regions were examined: entorhinal cortex, frontal cortex, and precuneus. However, whole-transcript expression arrays were carried out in the entorhinal cortex in 5 controls and $5 \mathrm{AD}$ cases stage V-VI. These cases were accepted once the RNA integrity number (RIN) values were considered sufficient to perform RNA studies. A summary of the cases used for mRNA studies are shown in Table 1.

In addition to these cases, $A D$ samples $(n=16)$ of the entorhinal cortex stages from stages ranging AD I-II ( 3 women and 4 men, aged between 55 and 79 years), AD III-IV ( 2 men and 2 women, aged between 68 and 80 years), and V-VI ( 1 women and 4 men, aged between 75 and 87 years) in comparison with control cases $(n=4)$ were added for metabolomics studies. The postmortem delay in all these cases was between 3 hours 45 minutes and 9 hours 30 minutes, and particular attention was paid to include cases with short or sudden agonic state, renal, hepatic, and respiratory insufficiency, infections and neoplasia, in addition to those criteria referred previously.

\subsection{Whole-transcript expression arrays}

RNA samples from entorhinal cortex of control and AD cases were analyzed using the Affymetrix microarray platform and the Genechip Affymetrix Human Exon 1.0 ST Array. This array analyzes 
Table 1

Summary of the main clinical and pathologic features of the cases used for mRNA expression studies

\begin{tabular}{|c|c|c|c|c|c|c|c|}
\hline \multirow[t]{2}{*}{ Case } & \multirow[t]{2}{*}{ Gender } & \multirow{2}{*}{$\begin{array}{l}\text { Age } \\
\text { (y) }\end{array}$} & \multirow[t]{2}{*}{ PMD } & \multirow{2}{*}{$\begin{array}{l}\text { Neuropathologic } \\
\text { diagnosis }\end{array}$} & \multicolumn{3}{|c|}{ RIN values } \\
\hline & & & & & $\overline{\mathrm{EC}}$ & PC & $\overline{\mathrm{FC}}$ \\
\hline 1 & $\mathrm{M}$ & 75 & $3 \mathrm{~h}$ & $\mathrm{C}$ & & & 6.5 \\
\hline 2 & $\mathrm{M}$ & 62 & $3 \mathrm{~h}$ & $\mathrm{C}$ & & & 7.2 \\
\hline 3 & $\mathrm{M}$ & 67 & $5 \mathrm{~h}$ & $\mathrm{C}$ & & & 7 \\
\hline 4 & $\mathrm{M}$ & 55 & $16 \mathrm{~h}$ & $\mathrm{C}$ & & & 7.4 \\
\hline 5 & $\mathrm{M}$ & 56 & $5 \mathrm{~h}$ & $\mathrm{C}$ & & & 7.1 \\
\hline 6 & $\mathrm{M}$ & 57 & $5 \mathrm{~h} 20 \mathrm{~min}$ & $\mathrm{C}$ & 7.3 & & \\
\hline 7 & W & 66 & $4 \mathrm{~h} 15 \mathrm{~min}$ & $\mathrm{C}$ & 6.9 & 7 & \\
\hline 8 & $\mathrm{M}$ & 49 & $7 \mathrm{~h}$ & $\mathrm{C}$ & & & 8.2 \\
\hline 9 & $\mathrm{M}$ & 53 & $3 \mathrm{~h}$ & $\mathrm{C}$ & & & 7.7 \\
\hline 10 & $\mathrm{M}$ & 59 & $7 \mathrm{~h} 5 \mathrm{~min}$ & $\mathrm{C}$ & & & 7.9 \\
\hline 11 & $\mathrm{M}$ & 46 & $9 \mathrm{~h} 35 \mathrm{~min}$ & $\mathrm{C}$ & & & 7.2 \\
\hline 12 & $\mathrm{M}$ & 56 & $3 \mathrm{~h} 50 \mathrm{~min}$ & $\mathrm{C}$ & & & 7.1 \\
\hline 13 & $\mathrm{M}$ & 52 & $4 \mathrm{~h} 40 \mathrm{~min}$ & $\mathrm{C}$ & & & 7.9 \\
\hline 14 & $\mathrm{~W}$ & 52 & $5 \mathrm{~h} 45 \mathrm{~min}$ & $\mathrm{C}$ & 6.6 & & \\
\hline 15 & $\mathrm{~W}$ & 71 & $8 \mathrm{~h} 30 \mathrm{~min}$ & $\mathrm{C}$ & & & 7.4 \\
\hline 16 & $\mathrm{M}$ & 61 & $3 \mathrm{~h} 40 \mathrm{~min}$ & $\mathrm{C}$ & 6.9 & 7.7 & \\
\hline 17 & $\mathrm{M}$ & 65 & $2 \mathrm{~h} 15 \mathrm{~min}$ & $\mathrm{C}$ & 7.3 & 7.8 & \\
\hline 18 & $\mathrm{~W}$ & 79 & $3 \mathrm{~h} 35 \mathrm{~min}$ & $\mathrm{C}$ & 7.3 & & \\
\hline 19 & $\mathrm{~W}$ & 79 & $3 \mathrm{~h} 35 \mathrm{~min}$ & $\mathrm{C}$ & & & 8 \\
\hline 20 & $\mathrm{~W}$ & 79 & $6 \mathrm{~h} 25 \mathrm{~min}$ & $\mathrm{C}$ & 7.1 & & \\
\hline 21 & $\mathrm{~W}$ & 79 & $6 \mathrm{~h} 25 \mathrm{~min}$ & $\mathrm{C}$ & & & 6.4 \\
\hline 22 & $\mathrm{M}$ & 64 & $8 \mathrm{~h} 35 \mathrm{~min}$ & $\mathrm{C}$ & & & 7.7 \\
\hline 23 & $\mathrm{~W}$ & 64 & $5 \mathrm{~h}$ & $\mathrm{C}$ & 6.9 & 8 & \\
\hline 24 & $\mathrm{~W}$ & 77 & $3 \mathrm{~h} 15 \mathrm{~min}$ & $\mathrm{C}$ & 7.2 & & \\
\hline 25 & $\mathrm{~W}$ & 77 & $3 \mathrm{~h} 15 \mathrm{~min}$ & $\mathrm{C}$ & & & 7 \\
\hline 26 & $\mathrm{M}$ & 79 & $4 \mathrm{~h} 15 \mathrm{~min}$ & $\mathrm{C}$ & 7.2 & 6.6 & \\
\hline 27 & $\mathrm{~W}$ & 76 & $5 \mathrm{~h} 45 \mathrm{~min}$ & $\mathrm{C}$ & & & 8.3 \\
\hline 28 & $\mathrm{M}$ & 83 & $4 \mathrm{~h} 30 \mathrm{~min}$ & $\mathrm{C}$ & 8 & 8 & \\
\hline 29 & $\mathrm{M}$ & 71 & $5 \mathrm{~h} 15 \mathrm{~min}$ & $\mathrm{C}$ & 6.6 & 6.8 & \\
\hline 30 & $\mathrm{~W}$ & 86 & $4 \mathrm{~h} 15 \mathrm{~min}$ & $\mathrm{C}$ & 7.4 & & \\
\hline 31 & $\mathrm{~W}$ & 86 & $4 \mathrm{~h} 15 \mathrm{~min}$ & $\mathrm{C}$ & & & 8.4 \\
\hline 32 & $\mathrm{M}$ & 85 & $3 \mathrm{~h} 45 \mathrm{~min}$ & $\mathrm{C}$ & 8.2 & & \\
\hline 33 & $\mathrm{M}$ & 77 & $2 \mathrm{~h} 55 \mathrm{~min}$ & $\mathrm{C}$ & 7 & 8.2 & \\
\hline 34 & $\mathrm{M}$ & 80 & $3 \mathrm{~h} 30 \mathrm{~min}$ & $\mathrm{C}$ & 7.3 & 6.5 & \\
\hline 35 & $\mathrm{M}$ & 83 & $18 \mathrm{~h}$ & AD III & 6.8 & & \\
\hline 36 & $\mathrm{~W}$ & 77 & $11 \mathrm{~h} 30 \mathrm{~min}$ & AD III & 6.7 & & \\
\hline 37 & $\mathrm{M}$ & 90 & $2 \mathrm{~h} 30 \mathrm{~min}$ & AD III & & & 8.8 \\
\hline 38 & $\mathrm{M}$ & 81 & $4 \mathrm{~h}$ & AD III & 6.5 & & \\
\hline 39 & $\mathrm{M}$ & 81 & $4 \mathrm{~h}$ & AD III & & & 7.4 \\
\hline 40 & $\mathrm{M}$ & 82 & $3 \mathrm{~h} 45 \mathrm{~min}$ & AD III & 6.8 & & \\
\hline 41 & W & 76 & $9 \mathrm{~h} 50 \mathrm{~min}$ & AD III & & & 8.3 \\
\hline 42 & $\mathrm{M}$ & 69 & $13 \mathrm{~h} 10 \mathrm{~min}$ & AD III & 7.7 & 6.9 & \\
\hline 43 & $\mathrm{M}$ & 69 & $13 \mathrm{~h} 10 \mathrm{~min}$ & AD III & & & 8.8 \\
\hline 44 & $\mathrm{M}$ & 80 & $4 \mathrm{~h} 20 \mathrm{~min}$ & AD III & 6.7 & & \\
\hline 45 & W & 67 & $6 \mathrm{~h} 10 \mathrm{~min}$ & AD III & 6.6 & & \\
\hline 46 & $\mathrm{~W}$ & 67 & $6 \mathrm{~h} 10 \mathrm{~min}$ & AD III & & & 6.4 \\
\hline 47 & $\mathrm{~W}$ & 90 & $4 \mathrm{~h}$ & AD III & 6.9 & 6.9 & \\
\hline 48 & $\mathrm{~W}$ & 79 & $3 \mathrm{~h} 35 \mathrm{~min}$ & AD III & 7.7 & 7.7 & \\
\hline 49 & W & 79 & $3 \mathrm{~h} 35 \mathrm{~min}$ & AD III & & & 8.7 \\
\hline 50 & $\mathrm{M}$ & 77 & $5 \mathrm{~h} 40 \mathrm{~min}$ & AD III & 6.4 & 6.7 & \\
\hline 51 & $\mathrm{~W}$ & 82 & $3 \mathrm{~h} 05 \mathrm{~min}$ & AD III & 6.4 & 7.4 & \\
\hline 52 & $\mathrm{M}$ & 75 & $3 \mathrm{~h} 25 \mathrm{~min}$ & AD III & 7.3 & 7 & \\
\hline 53 & $\mathrm{M}$ & 75 & $6 \mathrm{~h} 10 \mathrm{~min}$ & AD IV & & & 6.8 \\
\hline 54 & $\mathrm{~W}$ & 90 & $9 \mathrm{~h} 55 \mathrm{~min}$ & AD IV & & & 6.5 \\
\hline 55 & $\mathrm{~W}$ & 81 & $5 \mathrm{~h}$ & AD IV & 6.4 & 7.2 & \\
\hline 56 & $\mathrm{~W}$ & 81 & $5 \mathrm{~h}$ & AD IV & & & 7.3 \\
\hline 57 & M & 79 & $4 \mathrm{~h} 15 \mathrm{~min}$ & AD IV & 7 & & \\
\hline 58 & $\mathrm{M}$ & 82 & $10 \mathrm{~h}$ & AD V & & & 6.4 \\
\hline 59 & $\mathrm{~W}$ & 86 & $10 \mathrm{~h}$ & $A D V$ & & & 7 \\
\hline 60 & $\mathrm{M}$ & 78 & $19 \mathrm{~h}$ & AD V & & & 6.9 \\
\hline 61 & $\mathrm{M}$ & 81 & $3 \mathrm{~h} 45 \mathrm{~min}$ & $A D V$ & & & 7.3 \\
\hline 62 & $\mathrm{~W}$ & 82 & $1 \mathrm{~h} 45 \mathrm{~min}$ & $A D V$ & & & 7.8 \\
\hline 63 & $\mathrm{M}$ & 72 & $2 \mathrm{~h} 45 \mathrm{~min}$ & $A D V$ & & & 7 \\
\hline 64 & $\mathrm{M}$ & 77 & $8 \mathrm{~h}$ & AD V & & & 7.7 \\
\hline 65 & $\mathrm{~W}$ & 96 & 17 h $35 \mathrm{~min}$ & $\mathrm{AD} \mathrm{V}$ & & & 7 \\
\hline 66 & $\mathrm{M}$ & 79 & $7 \mathrm{~h} 30 \mathrm{~min}$ & $A D V$ & & & 6.7 \\
\hline 67 & $\mathrm{M}$ & 73 & $4 \mathrm{~h} 30 \mathrm{~min}$ & AD V & & 7.4 & 8.5 \\
\hline 68 & $\mathrm{~W}$ & 85 & $16 \mathrm{~h} 15 \mathrm{~min}$ & AD V & 6.4 & 6.9 & \\
\hline 69 & $\mathrm{~W}$ & 85 & $16 \mathrm{~h} 15 \mathrm{~min}$ & $A D V$ & & & 7.9 \\
\hline 70 & $\mathrm{~W}$ & 74 & $5 \mathrm{~h} 30 \mathrm{~min}$ & AD V & & 7.5 & 8.7 \\
\hline 71 & $\mathrm{M}$ & 93 & $3 \mathrm{~h}$ & AD V & 7.6 & & \\
\hline 72 & $\mathrm{M}$ & 93 & $3 \mathrm{~h}$ & $\mathrm{AD} \mathrm{V}$ & & 7.8 & 7.8 \\
\hline
\end{tabular}


Table 1 (continued)

\begin{tabular}{|c|c|c|c|c|c|c|c|}
\hline \multirow[t]{2}{*}{ Case } & \multirow[t]{2}{*}{ Gender } & \multirow{2}{*}{$\begin{array}{l}\text { Age } \\
\text { (y) }\end{array}$} & \multirow[t]{2}{*}{ PMD } & \multirow{2}{*}{$\begin{array}{l}\text { Neuropathologic } \\
\text { diagnosis }\end{array}$} & \multicolumn{3}{|c|}{ RIN values } \\
\hline & & & & & $\mathrm{EC}$ & PC & FC \\
\hline 73 & $\mathrm{~W}$ & 81 & $5 \mathrm{~h} 15 \mathrm{~min}$ & AD V & & & 8.5 \\
\hline 74 & $\mathrm{M}$ & 75 & $11 \mathrm{~h} 30 \mathrm{~min}$ & AD V & & 6.3 & 6.4 \\
\hline 75 & $\mathrm{M}$ & 82 & $03 \mathrm{~h} 45 \mathrm{~min}$ & AD V & 7.4 & & \\
\hline 76 & $\mathrm{M}$ & 82 & $03 \mathrm{~h} 45 \mathrm{~min}$ & AD V & & 7.8 & 9.1 \\
\hline 77 & $\mathrm{M}$ & 77 & $16 \mathrm{~h}$ & AD V & & 6.8 & 6.5 \\
\hline 78 & $\mathrm{M}$ & 92 & $7 \mathrm{~h} 45 \mathrm{~min}$ & AD V & 6.8 & & \\
\hline 79 & W & 87 & $5 \mathrm{~h} 15 \mathrm{~min}$ & AD V & 6.4 & & \\
\hline 80 & W & 93 & $6 \mathrm{~h}$ & AD V & 7.4 & & \\
\hline 81 & $\mathrm{M}$ & 80 & $6 \mathrm{~h} 30 \mathrm{~min}$ & AD V & 7.9 & & \\
\hline 82 & $\mathrm{M}$ & 61 & 8 h $15 \mathrm{~min}$ & AD V & 6.6 & & \\
\hline 83 & W & 85 & $5 \mathrm{~h}$ & AD V & 6.8 & & \\
\hline 84 & $\mathrm{~W}$ & 85 & $12 \mathrm{~h} 10 \mathrm{~min}$ & AD VI & & & 6.7 \\
\hline 85 & $\mathrm{~W}$ & 86 & 20 h 35 min & AD VI & & & 7.5 \\
\hline 86 & W & 67 & $8 \mathrm{~h}$ & AD VI & 7 & & \\
\hline 87 & W & 67 & $8 \mathrm{~h}$ & AD VI & & & 8.2 \\
\hline 88 & $\mathrm{M}$ & 82 & $5 \mathrm{~h}$ & AD VI & 6.7 & & \\
\hline 89 & $\mathrm{M}$ & 84 & $5 \mathrm{~h}$ & AD VI & 7.6 & & \\
\hline 90 & $\mathrm{~W}$ & 85 & $5 \mathrm{~h} 45 \mathrm{~min}$ & AD VI & 6.9 & & \\
\hline 91 & $\mathrm{M}$ & 63 & $8 \mathrm{~h}$ & AD VI & 7 & & \\
\hline 92 & $\mathrm{M}$ & 75 & $6 \mathrm{~h} 40 \mathrm{~min}$ & AD VI & 6.7 & & \\
\hline
\end{tabular}

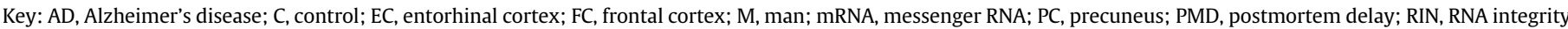
number; W, woman.

gene expression patterns on a whole-genome scale for a single array, with probes covering several exons on the target genes. Starting material was $200 \mathrm{ng}$ of total RNA of each sample. Quality of isolated RNA was first measured with Bioanalyzer Assay (Agilent). Sense single-stranded DNA suitable for labeling was generated from total RNA with the Ambion WT Expression Kit from Ambion (Carlsbad, CA, USA), according to the manufacturer's instructions. Sense single-stranded DNA was fragmented, labeled, and hybridized to the arrays with the GeneChip WT Terminal Labeling and Hybridization Kit from Affymetrix (Affymetrix, Santa Clara, CA, USA). Chips were processed on an Affymetrix Gene Titan platform. Microarray Data normalization and differential expression analysis preprocessing of raw data, and statistical analyses, were performed using Bioconductor packages in $\mathrm{R}$ programming environment (Gentleman et al., 2004). CEL files were read from Affymetrix arrays and corrected for the background. Resulting data were summarized and normalized with the microarray A method implemented in the
Bioconductor Limma package (Smyth, 2005). Furthermore, the fold change and standard errors were estimated by fitting a linear model (using the lmFit function in Limma package) for each gene given the groups of arrays. Genes with empirical Bayes $t$ test, $p$-values at a level of 0.05 were selected.

\subsection{RNA purification}

Purification of RNA from the right frontal cortex area 8, entorhinal cortex, and precuneus of AD samples and age-matched controls was carried out with RNeasy Lipid Tissue Mini Kit (Qiagen, Hilden, Germany) following the protocol provided by the supplier. During purification, samples were treated with RNase-free DNase Set (Qiagen) for 15 minutes to avoid extraction and later amplification of genomic DNA. The concentration of each sample was measured at $340 \mathrm{~nm}$ using a NanoDrop 2000 spectrophotometer (Thermo Scientific, Waltham, Massachussets, USA). RNA integrity was assessed

Table 2

TaqMan probes used for the study of expression of purine metabolism enzymes, including probes for normalization (GUS- $\beta$ )

\begin{tabular}{|c|c|c|}
\hline Gene & Full name & Sequence of TaqMan probes \\
\hline $\mathrm{ADA}$ & Adenosine deaminase & AGTTTAAAAGGCTGAACATCAATGC \\
\hline AK1 & Adenylate kinase 1 & AGTTTGAGCGACGGATTGGACAGCC \\
\hline AK2 & Adenylate kinase 2 & GGCAGGCAGAAATGCTCGATGACCT \\
\hline AK4 & Adenylate kinase 4 & ACTGGCTCCTTGATGGTTTTCCTAG \\
\hline AK5 & Adenylate kinase 5 & CTTTTGAGGACCAAATCTGTACCCC \\
\hline AK7 & Adenylate kinase 7 & GGAGACGTACTCTGCCATCTCTCAA \\
\hline APRT & Adenine phosphoribosyltransferase & CGCATCGACTACATCGCAGGCCTAG \\
\hline DGUOK & Deoxyguanosine kinase & GCAACATTGCTGTGGGAAAGTCCAC \\
\hline ENTPD1 & Ectonucleoside triphosphate diphosphohydrolase 1 & TCATTGGCAAGATCCAGGGCAGCGA \\
\hline ENTPD2 & Ectonucleoside triphosphate diphosphohydrolase 2 & CCCGCCCTCAAGTATGGCATCGTCC \\
\hline ENTPD3 & Ectonucleoside triphosphate diphosphohydrolase 3 & TGAAAAAGAAGTGGGGAATAGCAGC \\
\hline GUS-B & B-glucuronidase & GCTACTACTTGAAGATGGTGATCGC \\
\hline NME1 & Non-metastatic cells 1, protein (NM23A) expressed in (nucleoside-diphosphate kinase) & TGTTACCATCCCCGACCATCTGATT \\
\hline NME3 & Non-metastatic cells 3, protein expressed in (nucleoside-diphosphate kinase) & ATCGAGGTTGGCAAGAACCTGATTC \\
\hline NME4 & Non-metastatic cells 4, protein expressed in (nucleoside-diphosphate kinase) & GTCCACATCAGCAGGAATGTCATCC \\
\hline NME5 & Non-metastatic cells 5 , protein expressed in (nucleoside-diphosphate kinase) & TTTTATGTTTCCTGAAGTGATTGTT \\
\hline NME6 & Non-metastatic cells 6 , protein expressed in (nucleoside-diphosphate kinase) & CCACTGATTCTGGAGGCTGTTCATC \\
\hline NME7 & Non-metastatic cells 7, protein expressed in (nucleoside-diphosphate kinase) & CTGATCCTGAAATTGCCCGGCATTT \\
\hline NT5C & $5^{\prime}, 3^{\prime}$-nucleotidase, cytosolic & TGCGGCCCGACCTGGCGGATAAAGT \\
\hline NT5E & $5^{\prime}$-nucleotidase, ecto (CD73) & TTCTTTACACAGGCAATCCACCTTC \\
\hline NUDT1 & Nudix (nucleoside diphosphate-linked moiety X)-type motif 1 & ATGGGGCTAGGAGGGAGCTGCAGGA \\
\hline PNP & Purine nucleoside phosphorylase & GGGAGCAGACGCTGTTGGCATGAGT \\
\hline POLR3B & Polymerase (RNA) III (DNA directed) polypeptide B & GGTATTCTGGCTGGTGCCATTACTG \\
\hline PRUNE & Prune homolog (drosophila) & CCСTTCTGCATGGAACCATCATCCT \\
\hline
\end{tabular}




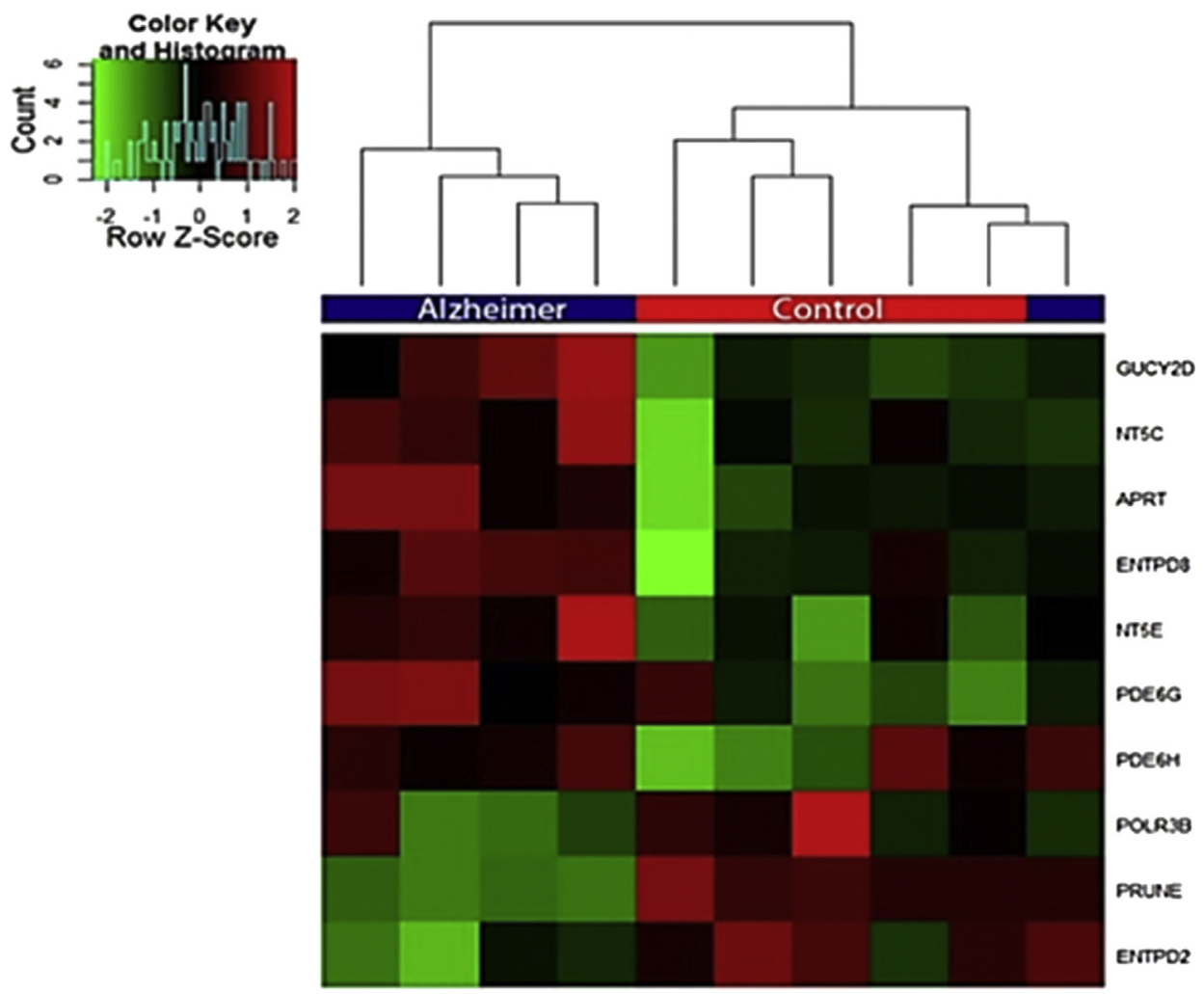

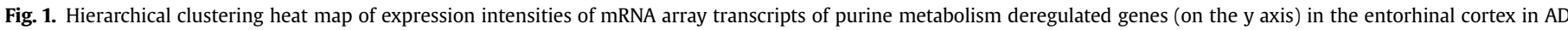

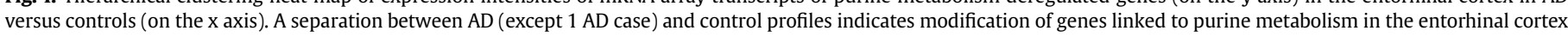
in $\mathrm{AD}$. Abbreviations: AD, Alzheimer's disease; mRNA, messenger RNA.

with the RIN determined with the Agilent 2100 Bioanalyzer (Agilent, Santa Clara, CA, USA). RIN values for each sample are shown in Table 1.

\subsection{Retrotranscription reaction}

Retrotranscription reaction of RNA samples selected based on their RIN values was carried out with the High-Capacity cDNA Archive kit (Applied Biosystems, Foster City, CA, USA) following the guidelines provided by the manufacturer and using Gene Amp 9700 PCR System thermocycler (Applied Biosystems). A parallel reaction for 1 RNA sample was processed in parallel in the absence of reverse transcriptase to rule out DNA contamination.

\subsection{Real-time polymerase chain reaction}

Polymerase chain reaction (PCR) assays were conducted in duplicate on cDNA samples obtained from the retrotranscription reaction, diluted 1:20 in 384-well optical plates (Kisker Biotech, Steinfurt, Germany) utilizing the ABI Prism 7900 HT Sequence Detection System (Applied Biosystems). Parallel amplification reactions were carried out using $20 \times$ TaqMan Gene Expression Assays for purine metabolism enzymes and $2 \times$ TaqMan Universal PCR Master Mix (Applied Biosystems). TaqMan probes used in the study are shown in Table 2. The reactions were performed following the parameters: $50^{\circ} \mathrm{C}$ for 2 minutes, $95^{\circ} \mathrm{C}$ for 10 minutes, 40 cycles at $95^{\circ} \mathrm{C}$ for 15 seconds, and $60^{\circ} \mathrm{C}$ for 1 minute. TaqMan PCR data were captured using the Sequence Detection Software (SDS version 2.2, Applied Biosystems). Subsequently, threshold cycle (CT) data for each sample were analyzed with the double delta CT $(\Delta \Delta C T)$ method. First, delta $C T(\Delta C T)$ values were calculated as the normalized CT values of each target gene in relation to the endogenous control $\beta$-glucuronidase (GUS- $\beta$ ). X-prolyl aminopepidase P1 (XPNPEP1) was also used as a putative housekeeping gene with suboptimal results, and therefore, XPNPEP1 was discarded. Second, $\Delta \Delta \mathrm{CT}$ values were obtained from the $\Delta \mathrm{CT}$ of each sample minus the mean $\Delta C T$ of the population of control samples (calibrator samples). The fold change was determined using the equation $2^{-\Delta \Delta \mathrm{CT}}$. Mean fold-change values for every region and stage between $\mathrm{AD}$ and age-matched controls were analyzed with the Student $t$ test using the Statgraphics Statistical Analysis and Data Visualization Software version 5.1. Differences between groups were considered statistically significant at ${ }^{*} p<0.05$, ${ }^{* *} p<$ 0.01 , and ${ }^{* * *} p<0.001$.

\subsection{Metabolomic analyses}

Tissue samples (50-70 mg) were homogenized using 20 volumes of cold methanol, containing $1 \mu \mathrm{M}$ butylhydroxytoluene as antioxidant. Then, samples were incubated for 1 hour at $20^{\circ} \mathrm{C}$ and centrifuged for 3 minutes at $12,000 \mathrm{~g}$. The supernatant was recovered, evaporated using a Speed Vac (Thermo Fisher Scientific, Barcelona, Spain), and resuspended in water $0.4 \%$ acetic acid:methanol (1:1). Metabolite extracts were subjected to mass spectrometry using an HPLC 1290 series coupled to an ESI-Q-TOF MS/MS 6520 (Agilent Technologies, Santa Clara, CA, USA). Specifically, $2 \mu \mathrm{L}$ of sample extract was applied to a reversed-phase column (Zorbax SBAq $1.8 \mu \mathrm{m} 2.1 \times 50 \mathrm{~mm}$; Agilent Technologies, Barcelona, Spain) equipped with a precolumn (Zorbax-SB-C8 Rapid Resolution Cartridge $2.1 \times 30 \mathrm{~mm} 3.5 \mu \mathrm{m}$ ) with a column temperature set at $60^{\circ} \mathrm{C}$. The flow rate was $0.6 \mathrm{~mL} / \mathrm{min}$. Solvent A was composed of water containing $0.2 \%$ acetic acid, and solvent B was composed of methanol $0.2 \%$ acetic acid. The gradient started in $2 \% \mathrm{~B}$ and increased to 


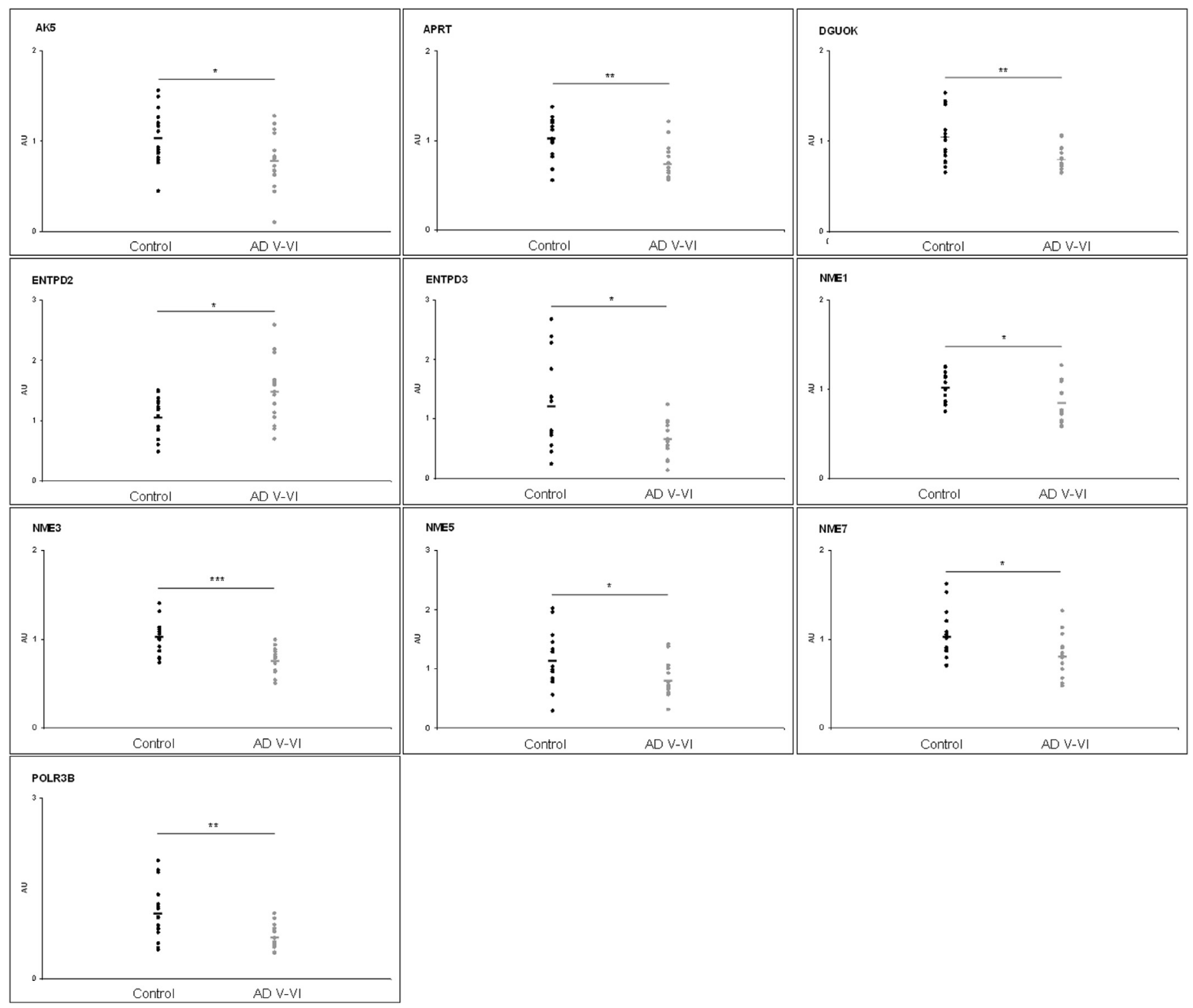

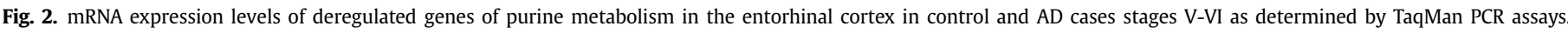

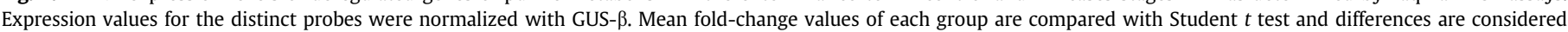

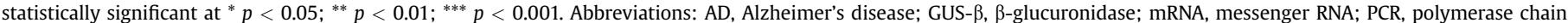
reaction.

98\% B in 13 minutes and held at $98 \%$ B for 6 minutes. Post time was established in 5 minutes, as previously described (Jové et al., 2011).

Data were collected in positive and negative electrospray mode time of flight operated in full-scan mode at $100-3000 \mathrm{~m} / \mathrm{z}$ in an extended dynamic range ( $2 \mathrm{GHz}$ ), using $\mathrm{N}_{2}$ as the nebulizer gas ( $5 \mathrm{~L}$ / $\min , 350{ }^{\circ} \mathrm{C}$ ). The capillary voltage was $3500 \mathrm{~V}$ with a scan rate of 1 scan/s. The ESI source used a separate nebulizer for the continuous, low-level (10 L/min) introduction of reference mass compounds: 121.050873, 922.009798 (positive ion mode) and 119.036320, 966.000725 (negative ion mode), which were used for continuous, online mass calibration. The Masshunter Data Analysis Software A.02.00 (Agilent Technologies, Barcelona, Spain) was used to collect the results, and the Masshunter Qualitative Analysis Software (Agilent Technologies, Barcelona, Spain) was used to obtain the molecular features of the samples, representing different, co-migrating ionic species of a given molecular entity using the Molecular Feature Extractor algorithm (Agilent Technologies, Barcelona, Spain), as described (Jové et al., 2011; Sana et al., 2008). Finally, the Masshunter
Mass Profiler Professional Software (Agilent Technologies, Barcelona, Spain) was used to perform a nontargeted metabolomic analysis of the extracted features. We selected samples with a minimum absolute abundance of 5000 counts and with a minimum of 2 ions. Multiple charge states were not considered. Compounds from different samples were aligned using an retention time window of $0.1 \% \pm 0.15$ minutes and a mass window of $5.0 \mathrm{ppm} \pm 2.0 \mathrm{mDa}$. Only common features (found in at least $75 \%$ of the samples of the same condition) were analyzed, correcting for individual bias. Data for hierarchical clustering were obtained using this software. The masses with significant differences in abundance (determined using a Student $t$ test; fold change $\geq 2, p<0.05$, multiple testing correction: Benjamini-Hochberg) were searched against the various databases. We performed identification of differential metabolites using the database PCDL from Agilent (Agilent Technologies), which uses retention times in a standardized chromatographic system as an orthogonal searchable parameter to complement accurate mass data 
Table 3

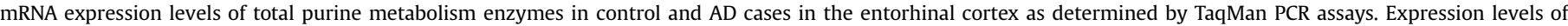
controls, AD III-IV, and AD V-VI cases using GUS- $\beta$ for normalization

\begin{tabular}{|c|c|c|c|c|c|}
\hline Probe & C & AD III-IV & AD V-VI & $C$ versus AD III-IV & $C$ versus $A D V-V I$ \\
\hline ADA & $1.04 \pm 0.32$ & $0.99 \pm 0.31$ & $0.81 \pm 0.29$ & - & - \\
\hline AK1 & $1.04 \pm 0.29$ & $1.05 \pm 0.32$ & $1.08 \pm 0.20$ & - & - \\
\hline AK2 & $1.01 \pm 0.16$ & $0.98 \pm 0.15$ & $0.98 \pm 0.13$ & - & - \\
\hline AK4 & $1.07 \pm 0.38$ & $1.03 \pm 0.30$ & $0.94 \pm 0.24$ & - & - \\
\hline AK5 & $1.04 \pm 0.30$ & $0.98 \pm 0.32$ & $0.78 \pm 0.31$ & - & $\downarrow^{*}$ \\
\hline AK7 & $1.13 \pm 0.58$ & $0.97 \pm 0.39$ & $1.10 \pm 0.86$ & - & - \\
\hline APRT & $1.03 \pm 0.23$ & $0.87 \pm 0.21$ & $0.76 \pm 0.19$ & - & $\downarrow^{* *}$ \\
\hline DGUOK & $1.04 \pm 0.29$ & $1.00 \pm 0.29$ & $0.81 \pm 0.13$ & - & $\downarrow^{* *}$ \\
\hline ENTPD1 & $1.05 \pm 0.30$ & $1.02 \pm 0.19$ & $1.20 \pm 0.31$ & - & - \\
\hline ENTPD2 & $1.06 \pm 0.33$ & $1.17 \pm 0.33$ & $1.48 \pm 0.53$ & - & $\uparrow^{*}$ \\
\hline ENTPD3 & $1.22 \pm 0.76$ & $0.99 \pm 0.42$ & $0.66 \pm 0.31$ & - & $\downarrow *$ \\
\hline NME1 & $1.01 \pm 0.17$ & $0.93 \pm 0.26$ & $0.83 \pm 0.22$ & - & $\downarrow^{*}$ \\
\hline NME3 & $1.02 \pm 0.19$ & $0.92 \pm 0.26$ & $0.75 \pm 0.14$ & - & $\downarrow^{* * *}$ \\
\hline NME4 & $1.03 \pm 0.27$ & $1.06 \pm 0.21$ & $1.03 \pm 0.21$ & - & - \\
\hline NME5 & $1.11 \pm 0.49$ & $1.09 \pm 0.36$ & $0.81 \pm 0.30$ & - & $\downarrow^{*}$ \\
\hline NME6 & $1.03 \pm 0.25$ & $1.04 \pm 0.25$ & $0.95 \pm 0.18$ & - & - \\
\hline NME7 & $1.03 \pm 0.29$ & $0.89 \pm 0.28$ & $0.82 \pm 0.24$ & - & $\downarrow^{*}$ \\
\hline NT5C & $1.01 \pm 0.13$ & $1.05 \pm 0.22$ & $1.01 \pm 0.22$ & - & - \\
\hline NT5E & $1.11 \pm 0.50$ & $1.09 \pm 0.54$ & $0.84 \pm 0.25$ & - & - \\
\hline NUDT1 & $1.08 \pm 0.34$ & $0.95 \pm 0.19$ & $0.95 \pm 0.16$ & - & - \\
\hline PNP & $1.10 \pm 0.49$ & $1.11 \pm 0.48$ & $0.97 \pm 0.44$ & - & - \\
\hline POLR3B & $1.09 \pm 0.46$ & $0.83 \pm 0.30$ & $0.69 \pm 0.20$ & - & $\downarrow^{* *}$ \\
\hline PRUNE & $1.04 \pm 0.28$ & $1.15 \pm 0.14$ & $0.91 \pm 0.19$ & - & - \\
\hline
\end{tabular}

Student $t$ test ${ }^{*} p<0.05,{ }^{* *} p<0.01$, and ${ }^{* * *} p<0.001$

Key: AD, Alzheimer's disease; C, control; GUS- $\beta$, $\beta$-glucuronidase; mRNA, messenger RNA; PCR, polymerase chain reaction.

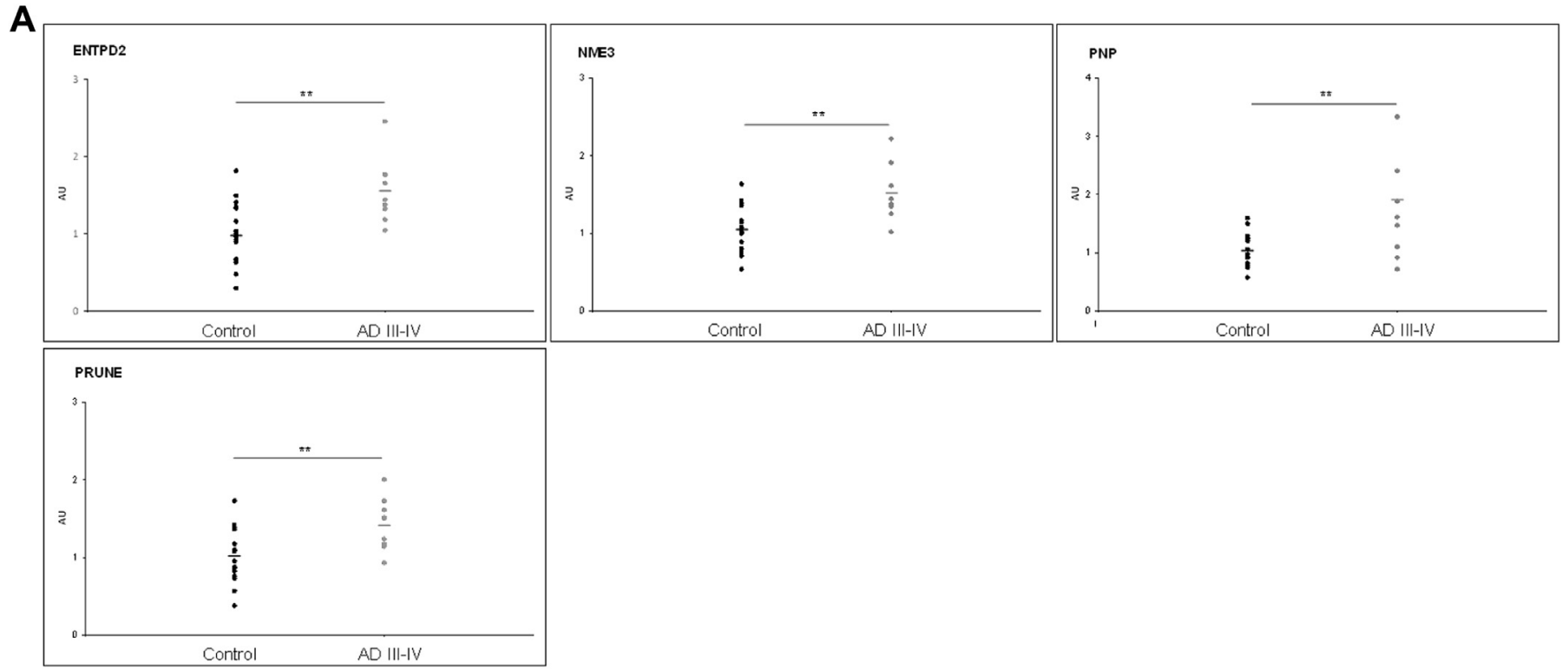

B

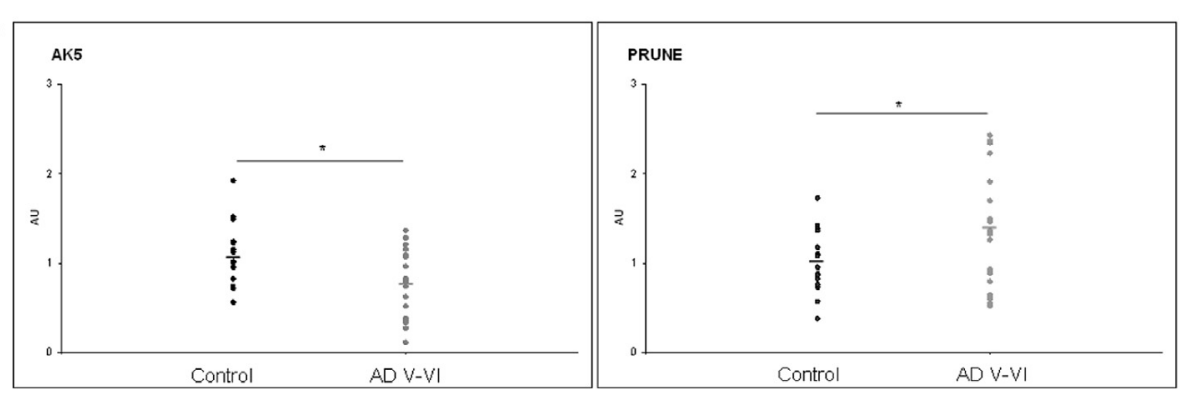

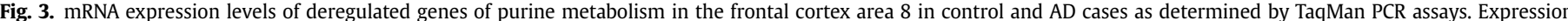

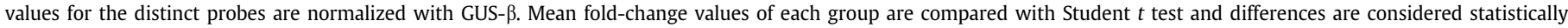

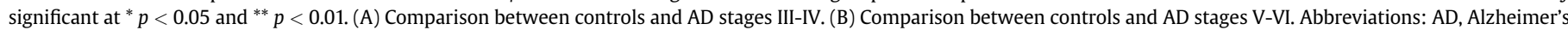
disease; GUS- $\beta$, $\beta$-glucuronidase; mRNA, messenger RNA; PCR, polymerase chain reaction. 
Table 4

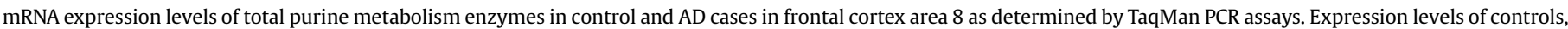
AD III-IV, and AD V-VI cases using GUS- $\beta$ for normalization

\begin{tabular}{|c|c|c|c|c|c|}
\hline Probe & C & AD III-IV & AD V-VI & $C$ versus AD III-IV & $C$ versus $A D$ V-VI \\
\hline ADA & $1.07 \pm 0.40$ & $1.25 \pm 0.56$ & $1.14 \pm 0.40$ & - & - \\
\hline AK1 & $1.11 \pm 0.46$ & $1.30 \pm 0.19$ & $1.41 \pm 0.56$ & - & - \\
\hline AK2 & $1.01 \pm 0.17$ & $1.11 \pm 0.12$ & $1.06 \pm 0.22$ & - & - \\
\hline AK4 & $1.14 \pm 0.52$ & $1.35 \pm 0.33$ & $1.12 \pm 0.52$ & - & - \\
\hline AK5 & $1.05 \pm 0.36$ & $0.93 \pm 0.25$ & $0.78 \pm 0.38$ & - & $\downarrow^{*}$ \\
\hline AK7 & $1.05 \pm 0.32$ & $1.24 \pm 0.34$ & $1.22 \pm 0.42$ & - & - \\
\hline APRT & $1.06 \pm 0.35$ & $1.21 \pm 0.20$ & $1.09 \pm 0.50$ & - & - \\
\hline DGUOK & $1.09 \pm 0.42$ & $1.24 \pm 0.27$ & $1.15 \pm 0.52$ & - & - \\
\hline ENTPD1 & $1.08 \pm 0.40$ & $1.30 \pm 0.41$ & $1.29 \pm 0.55$ & - & - \\
\hline ENTPD2 & $1.00 \pm 0.41$ & $1.55 \pm 0.42$ & $1.19 \pm 0.41$ & $\uparrow^{* *}$ & - \\
\hline ENTPD3 & $1.18 \pm 0.66$ & $0.90 \pm 0.38$ & $0.81 \pm 0.55$ & - & - \\
\hline NME1 & $1.09 \pm 0.48$ & $1.11 \pm 0.33$ & $0.98 \pm 0.58$ & - & - \\
\hline NME3 & $1.04 \pm 0.29$ & $1.50 \pm 0.36$ & $1.14 \pm 0.43$ & $\uparrow^{* *}$ & - \\
\hline NME4 & $1.04 \pm 0.32$ & $1.27 \pm 0.23$ & $1.10 \pm 0.54$ & - & - \\
\hline NME5 & $1.10 \pm 0.49$ & $1.10 \pm 0.27$ & $0.95 \pm 0.53$ & - & - \\
\hline NME6 & $1.06 \pm 0.38$ & $1.27 \pm 0.35$ & $1.07 \pm 0.48$ & - & - \\
\hline NME7 & $1.09 \pm 0.45$ & $1.06 \pm 0.24$ & $0.97 \pm 0.54$ & - & - \\
\hline NT5C & $1.05 \pm 0.32$ & $1.36 \pm 0.52$ & $1.10 \pm 0.25$ & - & - \\
\hline NT5E & $1.16 \pm 0.62$ & $1.44 \pm 0.60$ & $1.34 \pm 0.75$ & - & - \\
\hline NUDT1 & $1.03 \pm 0.25$ & $1.10 \pm 0.15$ & $1.02 \pm 0.24$ & - & - \\
\hline PNP & $1.04 \pm 0.29$ & $1.86 \pm 0.97$ & $1.09 \pm 0.54$ & $\uparrow^{* *}$ & - \\
\hline POLR3B & $1.14 \pm 0.53$ & $1.07 \pm 0.26$ & $1.12 \pm 0.58$ & - & - \\
\hline PRUNE & $1.02 \pm 0.34$ & $1.42 \pm 0.34$ & $1.37 \pm 0.63$ & $\uparrow^{* *}$ & $\uparrow^{*}$ \\
\hline
\end{tabular}

Student $t$ test $* p<0.05$ and ${ }^{* *} p<0.01$

Key: AD, Alzheimer's disease; C, control; GUS- $\beta$, $\beta$-glucuronidase; mRNA, messenger RNA; PCR, polymerase chain reaction.

(accurate mass retention time approach) according to previously published works (Sana et al., 2008).

\subsection{Pathway analyses and statistics}

Pathway analysis was performed using Metaboanalyst platform (Xia et al., 2012). Non-targeted metabolomics analyses were carried out using the MassHunter Mass Profiler Professional Software (Agilent Technologies, Barcelona, Spain). Other statistical calculations were performed using the SPSS software (SPSS, Chicago, IL, USA). Normality of variables' distribution was checked with the Kolmogorov-Smirnoff test. Differences in amount of molecules between groups were analyzed with 1-way ANOVA using Benjamini-Hochberg multiple testing correction. A $p<0.05$ level was selected as the point of minimal statistical significance in every comparison. Graphics were created with Graph Pad Prism (version 4.0; La Jolla, CA, USA).

\section{Results}

\subsection{Functional genomic analysis detects deregulation of purine metabolism in $A D$ entorhinal cortex}

Messenger RNA samples from $\mathrm{AD}(\mathrm{n}=5)$ and age-matched controls $(\mathrm{n}=5)$ were hybridized to an Affymetrix Human Exon 1.0 ST Array, which interrogates over 1 million exon clusters within the known and predicted transcribed regions of the entire genome. We found a differential expression of genes belonging to the Kyoto Encyclopedia of Genes and Genomes (KEGG) (Kanehisa and Goto, 2000) pathway "Purine Metabolism" (KEGG:00230). Modification of transcriptional profiles for these purine genes in $\mathrm{AD}$ was evidenced on the heat map representation of significantly regulated transcripts at probability of $p<0.05$ (Fig. 1).

\section{2. mRNA expression of purine metabolism enzymes in the human} entorhinal cortex in $A D$ at stages III-IV and $V$-VI

mRNA expression of 23 genes involved in purine metabolism was analyzed with TaqMan PCR. The symbol and names of the enzymes are shown in Table 2.
No differences were found in the mRNA expression levels of purine metabolism-related enzymes in the entorhinal cortex of $A D$ stages III-IV when compared with controls.

We found downregulation of APRT, DGUOK, POLR3B, ENTPD3, AK5, NME1, NME3, NME5, and NME7, whereas ENTPD2 mRNAs were upregulated in the entorhinal cortex of $A D$ stages $\mathrm{V}-\mathrm{VI}$ of Braak and Braak (Fig. 2). mRNA expression values for all probes normalized with GUS- $\beta$ in entorhinal cortex in AD stages V-VI and control cases are displayed in Table 3.

3.3. mRNA expression of purine metabolism enzymes in the human frontal cortex area 8 in $A D$ at stages III-IV and V-VI

To assess possible regional differences in the expression of genes related to purine metabolism in $\mathrm{AD}$ the frontal cortex was analyzed in similar cases.

In contrast to AD entorhinal cortex at stages III-IV, ENTPD2, NME3, PNP, and PRUNE mRNAs were significantly upregulated in the AD frontal cortex area 8 at stages III-IV compared with controls (Fig. 3).

Regarding stages V-VI, AK5 mRNA was found to be differentially downregulated and PRUNE mRNA upregulated in the frontal cortex when compared with controls (Fig. 3). mRNA expression values in the frontal cortex for all probes normalized with GUS- $\beta$ are shown in Table 4.

3.4. mRNA expression of purine metabolism enzymes in the precuneus in $A D$ at stages III-IV and V-VI

APRT, DGUOK, ENTPD3, POLR3B, NME3, and NME7 mRNAs were significantly downregulated, and ENTPD2 mRNA upregulated in the precuneus in AD stages III-IV in relation to controls (Fig. 4).

With regard to AD stages V-VI, NME3, NME4, and NME7 mRNA expression was decreased in comparison with controls when normalized with GUS- $\beta$ (Fig. 4). mRNA expression values in the precuneus for all probes normalized with GUS- $\beta$ are shown in Table 5. 
A
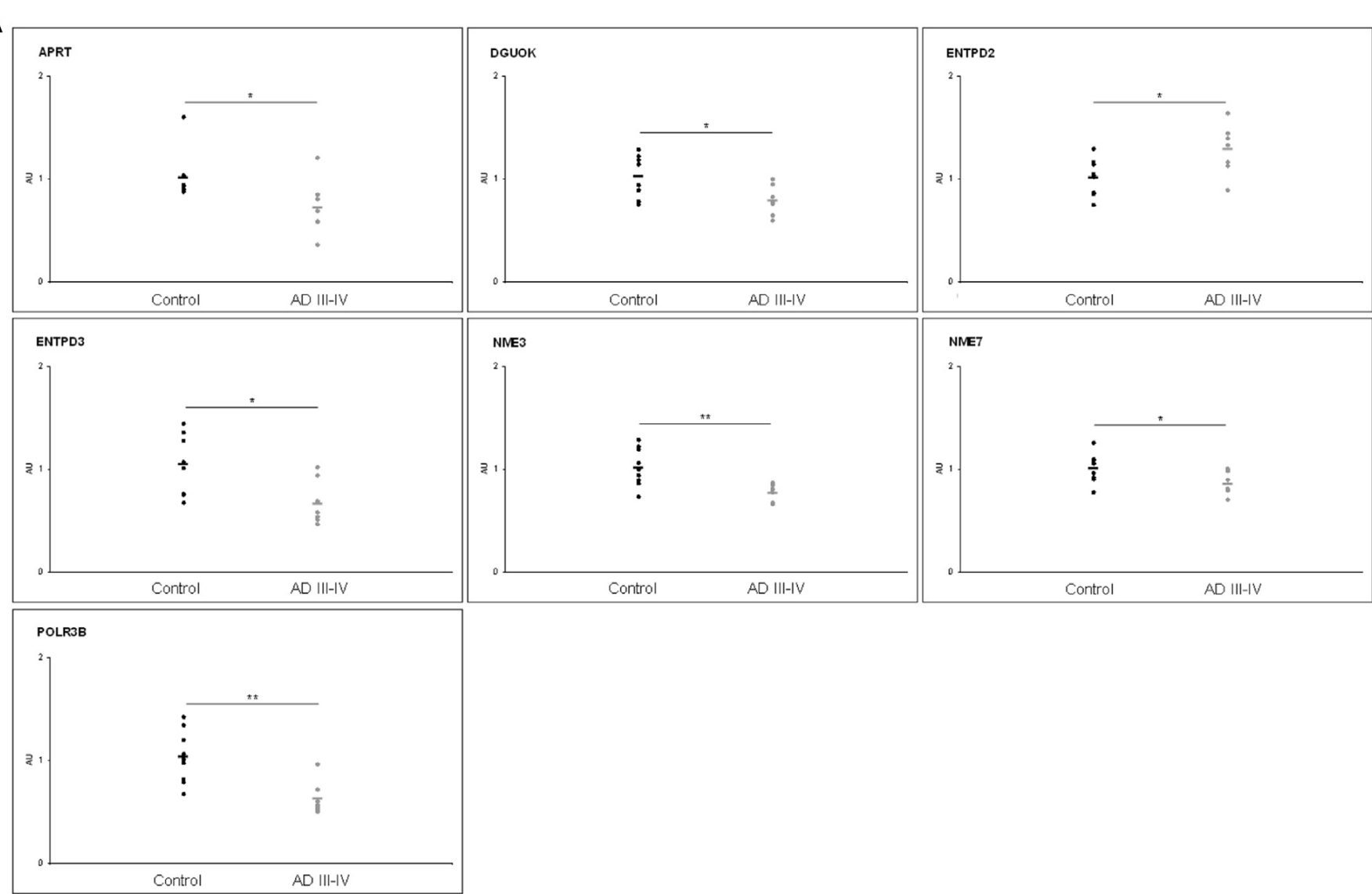

B
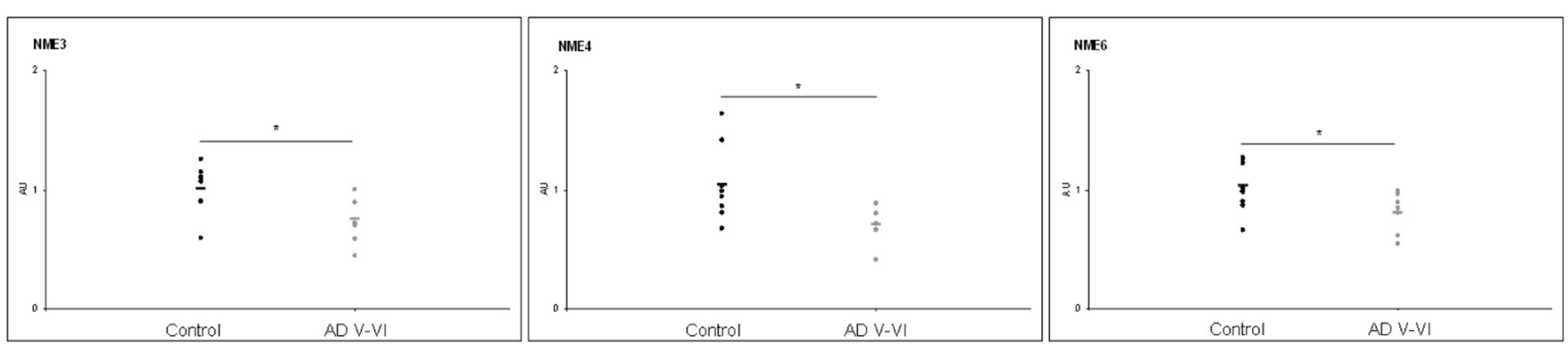

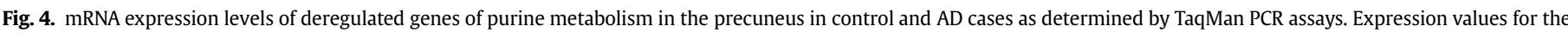

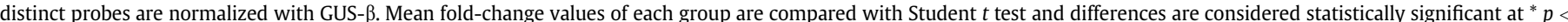

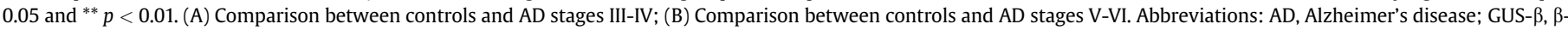
glucuronidase; mRNA, messenger RNA; PCR, polymerase chain reaction.

\subsection{Metabolomics results}

To extend and validate transcriptomic findings we performed untargeted metabolomics in selected entorhinal cortex samples. To learn about early metabolomics alterations, AD stages I-II were added to the study. First of all, using those molecules present in at least $75 \%$ of samples in the same group, hierarchical clustering analyses (Fig. 5A) showed the global profiling of the samples and the main differences between them, and demonstrated that $A D$ staging is a major factor for metabolomic profile discrimination. Thus, samples from control individual and stages V-VI of Braak and Braak clustered perfectly, whereas those of stages I-II and III-IV were more variable depending on the individual.

After metabolite identification using an orthogonal approach pathway analysis, one of the pathways with the most affected metabolites was related to purine metabolism. Specifically, taking only into account those molecules present in the database, 6 purine-related metabolites were seen to be affected by the disease and also by the stage (Fig. 5B). Among these, deoxyguanosine, guanine, and xanthosine changed at stages I-II of Braak and Braak and altered values at later stages; modifications in the expression of dGMP and glycine occurred at stages II-IV and persisted at stages VVI. Other metabolites marked advanced staging of $\mathrm{AD}$, such as inosine diphosphate (IDP). Globally, integrated biology showed a marked deviation of purine metabolism enzymes and metabolites in the entorhinal cortex in $\mathrm{AD}$ (Fig. 6).

\section{Discussion}

Global transcriptomics has identified deregulation of the purine metabolism pathway in the entorhinal cortex in AD. The transcriptomic study was performed on 23 AD cases at stages III-IV, $35 \mathrm{AD}$ 
Table 5

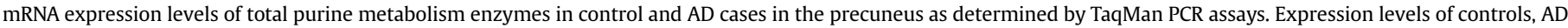
III-IV, and AD V-VI cases using GUS- $\beta$ for normalization

\begin{tabular}{|c|c|c|c|c|c|c|}
\hline Probe & $\mathrm{C}$ & AD III-IV & $\mathrm{C}^{*}$ & AD V-VI & $C$ versus AD III-IV & $\mathrm{C}^{*}$ versus $\mathrm{AD} \mathrm{V}-\mathrm{VI}$ \\
\hline $\mathrm{ADA}$ & $1.07 \pm 0.41$ & $0.81 \pm 0.31$ & $1.07 \pm 0.42$ & $0.65 \pm 0.35$ & - & - \\
\hline AK1 & $1.02 \pm 0.18$ & $1.17 \pm 0.09$ & $1.00 \pm 0.10$ & $1.15 \pm 0.40$ & & - \\
\hline AK2 & $1.01 \pm 0.12$ & $0.98 \pm 0.07$ & $1.03 \pm 0.29$ & $0.80 \pm 0.22$ & - & - \\
\hline AK4 & $1.02 \pm 0.22$ & $0.95 \pm 0.17$ & $1.05 \pm 0.35$ & $0.83 \pm 0.31$ & - & - \\
\hline AK5 & $1.02 \pm 0.23$ & $0.98 \pm 0.15$ & $1.06 \pm 0.39$ & $0.90 \pm 0.30$ & - & - \\
\hline AK7 & $1.03 \pm 0.29$ & $1.33 \pm 0.53$ & $1.02 \pm 0.23$ & $1.10 \pm 0.35$ & - & - \\
\hline APRT & $1.02 \pm 0.24$ & $0.72 \pm 0.27$ & NA & NA & $\downarrow *$ & NA \\
\hline DGUOK & $1.02 \pm 0.21$ & $0.79 \pm 0.15$ & $1.03 \pm 0.28$ & $0.81 \pm 0.23$ & $\downarrow *$ & - \\
\hline ENTPD1 & $1.01 \pm 0.15$ & $0.91 \pm 0.23$ & $1.04 \pm 0.16$ & $0.87 \pm 0.21$ & - & - \\
\hline ENTPD2 & $1.01 \pm 0.17$ & $1.28 \pm 0.24$ & $1.04 \pm 0.29$ & $0.90 \pm 0.31$ & $\uparrow^{*}$ & - \\
\hline ENTPD3 & $1.04 \pm 0.30$ & $0.67 \pm 0.22$ & $1.15 \pm 0.59$ & $0.92 \pm 0.27$ & $\downarrow *$ & - \\
\hline NME1 & $1.02 \pm 0.23$ & $1.01 \pm 0.18$ & $1.01 \pm 0.16$ & $0.93 \pm 0.33$ & - & - \\
\hline NME3 & $1.02 \pm 0.18$ & $0.77 \pm 0.08$ & $1.03 \pm 0.19$ & $0.75 \pm 0.19$ & $\downarrow * *$ & $\downarrow^{*}$ \\
\hline NME4 & $1.01 \pm 0.18$ & $1.06 \pm 0.29$ & $1.04 \pm 0.30$ & $0.72 \pm 0.16$ & - & $\downarrow *$ \\
\hline NME5 & $1.06 \pm 0.37$ & $0.88 \pm 0.12$ & $1.06 \pm 0.38$ & $0.99 \pm 0.31$ & - & - \\
\hline NME6 & $1.02 \pm 0.20$ & $0.89 \pm 0.12$ & $1.02 \pm 0.20$ & $0.81 \pm 0.17$ & - & $\downarrow *$ \\
\hline NME7 & $1.01 \pm 0.14$ & $0.86 \pm 0.11$ & $1.03 \pm 0.25$ & $0.94 \pm 0.30$ & $\downarrow$ * & - \\
\hline NT5C & $1.10 \pm 0.38$ & $1.21 \pm 0.24$ & $1.04 \pm 0.31$ & $0.97 \pm 0.25$ & - & - \\
\hline NT5E & $1.05 \pm 0.36$ & $0.81 \pm 0.37$ & $1.12 \pm 0.59$ & $0.94 \pm 0.28$ & - & - \\
\hline NUDT1 & $1.03 \pm 0.28$ & $1.03 \pm 0.15$ & $1.04 \pm 0.32$ & $1.13 \pm 0.19$ & - & - \\
\hline PNP & $1.07 \pm 0.40$ & $0.85 \pm 0.32$ & $1.05 \pm 0.35$ & $0.82 \pm 0.36$ & - & - \\
\hline POLR3B & $1.03 \pm 0.25$ & $0.63 \pm 0.16$ & $1.03 \pm 0.26$ & $0.93 \pm 0.31$ & $\downarrow$ ** & - \\
\hline PRUNE & $1.01 \pm 0.15$ & $0.92 \pm 0.15$ & $1.03 \pm 0.25$ & $0.94 \pm 0.22$ & - & - \\
\hline
\end{tabular}

Student $t$ test ${ }^{*} p<0.05$ and ${ }^{* *} p<0.01$.

Key: AD, Alzheimer's disease; $C$, control; GUS- $\beta$, $\beta$-glucuronidase; mRNA, messenger RNA; NA, not available; PCR, polymerase chain reaction.

cases at stages V-VI, and 34 controls, considering 23 selected genes and 3 cortical regions-entorhinal cortex, frontal cortex area 8 , and precuneus-using qRT-PCR. The selection of the 3 regions was based on the early involvement of the entorhinal cortex when compared with the frontal cortex area 8 (Braak and Braak, 1991) together with positron emission tomography identification of reduced cerebral glucose metabolism in the precuneus in AD (Herholz et al., 2007).

Viewed globally, the following genes have been found to be deregulated in AD when compared with controls: APRT, AK5, NME1, NME3, NME4, NME5, NME6, NME7, PRUNE, DGUOK, ENTPD2, ENTPD3, $P O L R B 3$, and $P N P$, although with variable extent depending on the region and the stage of the disease. Adenine phosphoribosyltransferase (encoded by APRT) is involved in the synthesis of AMP from adenine and guanosine monophosphate from guanine. APRT, whose defect in humans causes Lesch-Nyhan disease, has been recently implicated in Wnt signaling and presenilin-1 function (Kang et al., 2011), known targets of AD (Lee et al., 2010), thus reinforcing suspected links between purine metabolism and AD.

Adenylate kinase 5 (encoded by AK5), one member of the AK family, participates in the phosphorylation of AMP to adenosine diphosphate and dAMP to dATP (Dzeja and Terzic, 2009; Noma, 2005). In addition, adenylate kinase 5 interacts in brain with 14.3.3 complex (Angrand et al., 2006), a protein associated with tau deposition in neurofibrillary tangles (Qureshi et al., 2013).

The NME gene family encodes nucleotide diphosphate kinases and is composed of 10 genes, the products of which are involved in the phosphorylation of nucleotide diphosphates to form nucleotide triphosphates (i.e., guanosine triphosphate, ATP, dGTP, dATP, and dITP). This enzyme is especially present in the postsynaptic density fraction, supporting its relationship with synaptic function. Reduced mRNA expression of members of this family here identified agrees with previous results suggesting their decrease in $A D$ (Kim et al., 2002) and in AD-related transgenic mouse models (Liauw et al., 2002). In a close relationship with NME, PRUNE encodes prune exopolyphosphatase which participates in the metabolism of guanosine pentaphosphate and tetraphosphate in bacteria and is involved in the ability of RNA polymerases to initiate transcription. The human homolog $h$-PRUNE probably has similar functions. In addition to this metabolic function, it has also been involved in glyogenesis (Bilitou et al., 2012) and in brain development (Carotenuto et al., 2006), being mechanistically linked to NME in memory conservation (Li et al., 2012).

Deoxyguanosine kinase (encoded by DGUOK) phosphorylates purine deoxyribonucleosides in the mitochondrial matrix (Desvignes et al., 2009; Johansson et al., 2001; Jüllig and Eriksson, 2000). Its loss causes a complex mitochondriopathy with cerebral involvement (Mandel et al., 2001). DGUOK mutations have been reported in adult patients with mitochondrial DNA multiple deletions suffering from cognitive impairment (Ronchi et al., 2012). Furthermore, this enzyme is implicated in the regulation of neurite outgrowth (Loh et al., 2008).

ENTPD2 and ENTPD3, encoded by the genes ENTPD2 and ENTPD3, are 2 of the 8 members of ecto-nucleoside triphosphate diphosphohydrolases which hydrolyze the terminal phosphate group of nucleoside triphosphates and diphosphates, yielding diphosphates and monophosphates, respectively (Yegutkin, 2008). ENTPD2 and ENTPD3 dephosphorylate triphosphosphate nucleosides (guanosine triphosphate, AMP, and IDP) to their monophosphate form. Nucleoside triphosphate diphosphohydrolases are enzymes controlling extracellular ATP concentration, and their products are physiological activators of P1 (adenosine-activated type I receptors: A1, A2A, A2B, and A3), P2 (nucleotide-activated type 2 ligand-gated or ionotropic P2X ion channels), and metabotropic P2Y receptors (Al-Rashida and Iqbal, 2014).

POLR3B encodes polymerase (RNA) III (DNA directed) polypeptide $B$ which is the largest subunit of RNA polymerase III responsible for synthesizing transfer and small ribosomal RNAs. Our results are in line with previous reports showing abnormal POLR3B mRNA splicing (Bai et al., 2013) and reduced POLR3B mRNA levels (Husseman et al., 2001).

Finally, purine nucleotide phosphorylase, encoded by PNP, reversibly catalyzes the phosphorolysis of purine nucleosides. Interestingly, G151S polymorphism in this gene is associated with faster progression of cognitive decline in AD (Tumini et al., 2007).

Regarding the entorhinal cortex, 10 of 24 genes analyzed are abnormally regulated in $\mathrm{AD}$ at stages $\mathrm{V}-\mathrm{VI}$; only one of them 

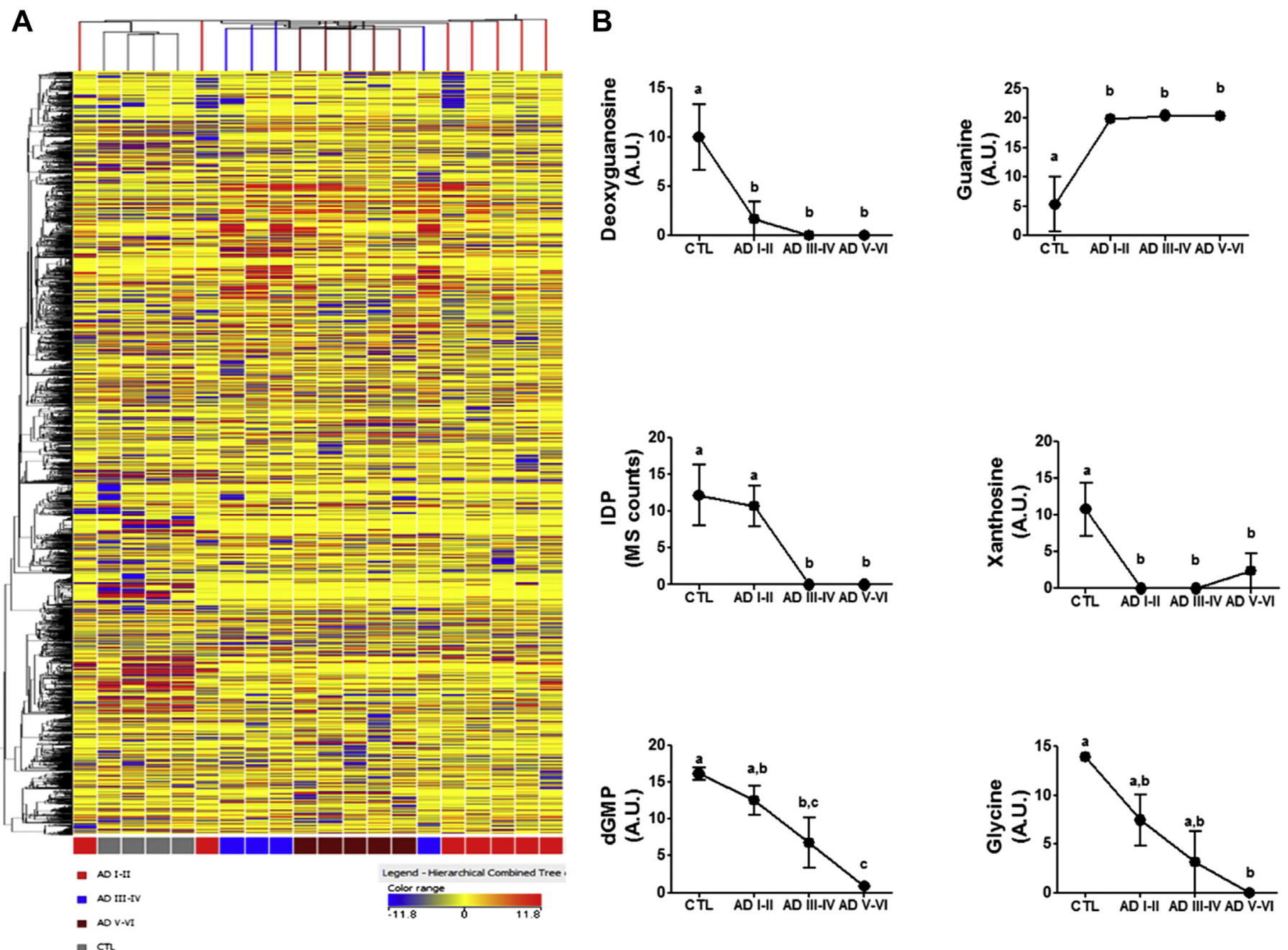

Fig. 5. Metabolomics of the entorhinal cortex in controls and AD stages I-II, III-IV, and V-VI of Braak and Braak. (A) Heat map representation of hierarchical clustering of molecular features found in sample. Each line of this figure represents an accurate mass, colored by its abundance intensity normalized to internal standard and baseline to median/mean across the samples. The scale from -11.8 (blue) to 11.8 (red) represents this normalized abundance in arbitrary units. (B) Normalized levels of purine-related pathway metabolites, with a, b, and c superindex indicating homogeneous subsets of metabolites by 1-way ANOVA Tukey post hoc analyses. Abbreviations: AD, Alzheimer's disease; ANOVA, analysis of variance. (For interpretation of the references to color in this figure, the reader is referred to the web version of this article.)

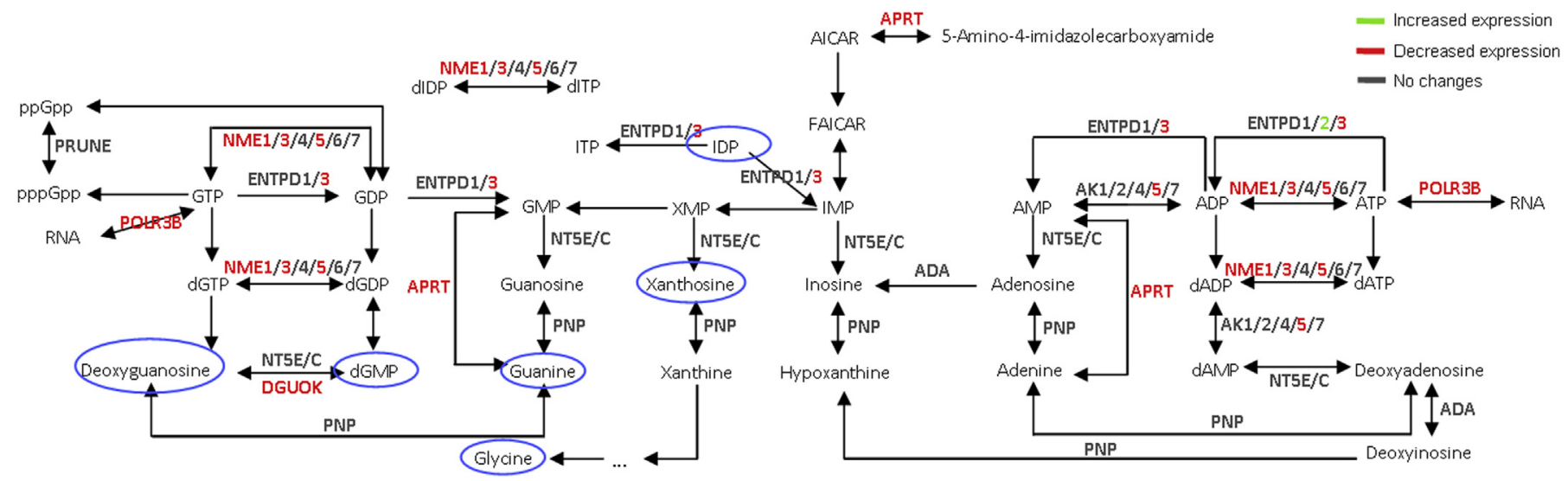

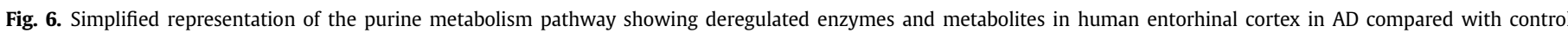

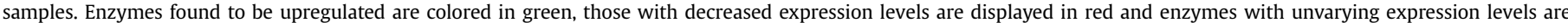

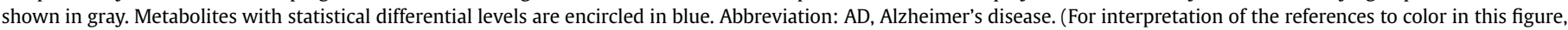
the reader is referred to the web version of this article.) 
(ENTPD2) is upregulated, whereas the other 9 are downregulated. A similar pattern was found involving only 7 of the 10 genes abnormally regulated in the entorhinal cortex also deregulated in the precuneus in AD at stages III-IV; ENTPD2 is upregulated and the other 6 downregulated. Curiously, only 2 new genes appear downregulated in the precuneus at stages V-VI. A very different profile occurs in the frontal cortex area 8 where 4 genes appear upregulated and none downregulated at stages III-IV, whereas only 1 gene is downregulated and none upregulated at stages V-VI.

Together, these findings indicate similar profiles of gene deregulation in $\mathrm{AD}$, albeit with different timings, in the entorhinal cortex and precuneus. The frontal cortex has a different regulation profile of genes involved in purine metabolism. These differences are not dependent on the stage of neurofibrillary tangle formation, as the precuneus and frontal cortex area 8 have no neurofibrillary tangle pathology at stages III-IV of Braak and Braak, whereas the entorhinal cortex is heavily affected by neurofibrillary tangles at stages III-IV. The regional distribution of senile plaques in the progression of AD (Braak and Braak, 1991, 1999) does not match the regional deregulation of genes controlling purine metabolism.

To learn about the consequences of altered gene regulation of purine metabolism using a completely different technique, massspectrometric based metabolomics was applied to the study of the entorhinal region at stages I-II, III-IV, and V-VI of Braak and Braak. It is important to stress that the half-life of several metabolites is measured in seconds, minutes, and a few hours. In consequence, metabolomics applied to postmortem human brain has benefits, as it can reveal long-lasting metabolites, but also limitations, as short-lived species vanish during the agonic stage and especially with the postmortem delay. Even considering these caveats, several altered metabolites have been identified in the entorhinal cortex including deoxyguanosine, dGMP, guanine, glycine, xanthosine, and IDP, thus supporting the idea that deregulation of genes involved in purine metabolism has functional effects. Interestingly, metabolomics in the entorhinal cortex has shown detectable changes in the expression levels of deoxyguanosine, xanthosine and guanine at stages I-II, followed by modifications in dGMP and glycine at stages III-IV. The explanation for the greater sensitivity of metabolomics than of transcriptomics to AD in early stages of AD may involve technical reasons or differing sensitivities to the disease of the outcome variable. Recent data show that metabolomics findings exceed what could be discerned from downstream analyses with transcriptomics (Tsai et al., 2013). In this line, posttranscriptional modification of enzymes could impinge on relevant changes in activity, without detectable alterations in mRNA transcripts, as exemplified by circadian regulation of enzyme activity (Robles et al., 2014).

In conclusion, changes in purine metabolism identified in the present study may affect the complex equilibrium between intracellular nucleoside triphosphates and the depending metabolites and products, including their export to extracellular space as neurocrine factors in $\mathrm{AD}$. The regional differences observed here point to the need for considering regional specificities as markers of regional vulnerability.

\section{Disclosure statement}

All authors declare that they do not have any actual or potential conflicts of interest including any financial, personal, or other relationships with other people or organizations within 3 years of beginning the work submitted that could inappropriately influence (bias) their work.

The human samples used in the present study have been obtained from the Institute of Neuropathology brain bank, a branch of the HUB-ICO-IDIBELL Brain Bank following the guidelines of the
Spanish legislation and the approval of the local ethics committee of the Bellvitge University Hospital.

\section{Acknowledgements}

This study was funded by the Seventh Framework Program of the European Commission, grant agreement 278486: DEVELAGE, and Institute Carlos III, FIS grant PI1100968, PI1101532, and PI1300584. Belen Ansoleaga is the recipient of a predoctoral grant from the "Programa de Formación de Personal Investigador no doctor del Departamento de Educación, Política Lingüística y Cultura" of the Basque Government. The authors thank T. Yohannan for editorial help.

\section{References}

Albasanz, J.L., Perez, S., Barrachina, M., Ferrer, I., Martín, M., 2008. Up-regulation of adenosine receptors in the frontal cortex in Alzheimer's disease. Brain Pathol. 18, 211-219.

Al-Rashida, M., Iqbal, J., 2014. Therapeutic potentials of ecto-nucleoside triphosphate diphosphohydrolase, ecto-nucleotide pyrophosphatase/phosphodiesterase, ecto-5'-nucleotidase, and alkaline phosphatase inhibitors. Med. Res. Rev. 34, 703-743.

Angrand, P.O., Segura, I., Völkel, P., Ghidelli, S., Terry, R., Brajenovic, M., Vintersten, K., Klein, R., Superti-Furga, G., Drewes, G., Kuste,r, B. Bouwmeester, T., Acker-Palmer, A., 2006. Transgenic mouse proteomics identifies new 14-3-3-associated proteins involved in cytoskeletal rearrangements and cell signaling. Mol. Cell. Proteomics 5, 2211-2227.

Angulo, E., Casadó, V., Mallol, J., Canela, E.I., Viñals, F., Ferrer, I., Lluis, C., Franco, R. 2003. A1 adenosine receptors accumulate in neurodegenerative structures in Alzheimer's disease and mediate both amyloid precursor protein processing and tau phosphorylation and translocation. Brain Pathol. 13, 440-451.

Bai, B., Hales, C.M., Chen, P.C., Gozal, Y., Dammer, E.B., Fritz, J.J., Wang, X., Xia, Q. Duong, D.M., Street, C., Cantero, G., Cheng, D., Jones, D.R., Wu, Z., Li, Y., Diner, I. Heilman, C.J., Rees, H.D., Wu, H., Lin, L., Szulwach, K.E., Gearing, M., Mufson, E.J., Bennett, D.A., Montine, T.J., Seyfried, N.T., Wingo, T.S., Sun, Y.E., Jin, P., Hanfelt, J., Willcock, D.M., Levey, A., Lah, J.J., Peng, J., 2013. U1 small nuclear ribonucleoprotein complex and RNA splicing alterations in Alzheimer's disease. Proc. Natl. Acad. Sci. U.S.A 110, 16562-16567.

Bilitou, A., De Marco, N., Bello, A.M., Garzia, L., Carotenuto, P., Kim, M., Campanella, C. Ohnuma, S., Zollo, M., 2012. Spatial and temporal expressions of prune reveal a role in Müller gliogenesis during Xenopus retinal development. Gene 509, 93-103.

Boison, D., 2008. Adenosine as a neuromodulator in neurological diseases. Curr. Opin. Pharmacol. 8, 2-7.

Braak, H., Alafuzoff, I., Arzberger, T., Kretzschmar, H., Del Tredici, K., 2006. Staging of Alzheimer disease-associated neurofibrillary pathology using paraffin sections and immunocytochemistry. Acta Neuropathol. 12, 389-404.

Braak, H., Braak, E., 1991. Neuropathological staging of Alzheimer-related changes. Acta Neuropathol. 82, 239-259.

Braak, H., Braak, E., 1999. Temporal sequence of Alzheimer's disease-related pathology. In: Peters, A., Morrison, J.H. (Eds.), Cereb. Cortex, Neurodegenerative and age-related changes in structure and function of cerebral cortex, 14. Kluwer Academic/Plenum Publishers, New York, Boston, Dordrecht, London, Moscow pp. 475-512.

Canepa, E., Domenicotti, C., Marengo, B., Passalacqua, M., Marinari, U.M., Pronzato, M.A., Fedele, E., Ricciarelli, R., 2013. Cyclic adenosine monophosphate as an endogenous modulator of the amyloid- $\beta$ precursor protein metabolism. IUBMB Life 65, 127-133.

Carman, A.J., Mills, J.H., Krenz, A., Kim, D.G., Bynoe, M.S., 2011. Adenosine receptor signaling modulates permeability of the blood-brain barrier. J. Neurosci. 31 $13272-13280$

Carotenuto, P., Marino, N., Bello, A.M., D’Angelo, A., Di Porzio, U., Lombardi, D., Zollo, M., 2006. PRUNE and NM23-M1 expression in embryonic and adult mouse brain. J. Bioenerg. Biomembr. 38, 233-246.

Dall'Igna, O.P., Porciúncula, L.O., Souza, D.O., Cunha, P.A., Lara, D.R., 2003. Neuroprotection by caffeine and adenosine $A_{2 A}$ receptor blockade of $\beta$-amyloid neurotoxicity. Br. J. Pharmacol. 138, 1207-1209.

Desvignes, T., Pontarotti, P., Fauvel, C., Bobe, J., 2009. NME protein family evolutionary history, a vertebrate perspective. BMC Evol. Biol. 9, 256.

Duyckaerts, C., Dickson, D., 2011. Neuropathology of Alzheimer's disease and its variants. In: Dickson, D., Weller, R. (Eds.), Neurodegeneration: The Molecular Pathology of Dementia and Movement Disorders. Wiley-Blackwell, West Sussex, pp. 62-91.

Dzeja, P., Terzic, A., 2009. Adenylate kinase and AMP signaling networks: metabolic monitoring, signal communication and body energy sensing. Int. J. Mol. Sci. 10 $1729-1772$.

Ferreira, I.L., Resende, R., Ferreiro, E., Rego, A.C., Pereira, C.F., 2010. Multiple defects in energy metabolism in Alzheimer's disease. Curr. Drug Targets 11, 1193-1206.

Ferrer, I., 2009. Altered mitochondria, energy metabolism, voltage-dependent anion channel, and lipid rafts converge to exhaust neurons in Alzheimer's disease. J. Bioenerg. Biomembr. 41, 425-431. 
Ferrer, I., 2012. Defining Alzheimer as a common age-related neurodegenerative process not inevitably leading to dementia. Prog. Neurobiol. 97, 38-51.

Gentleman, R.C., Carey, V.J., Bates, D.M., Bolstad, B., Dettling, M., Dudoit, S., Ellis, B., Gautier, L., Ge, Y., Gentry, J., Hornik, K., Hothorn, T., Huber, W., Iacus, S., Irizarry, R., Leisch, F., Li, C., Maechler, M., Rossini, A.J., Sawitzki, G., Smith, C., Smyth, G., Tierney, L., Yang, J.Y., Zhang, J., 2004. Bioconductor: open software development for computational biology and bioinformatics. Genome Biol. 5, R80.

Haass, C., Selkoe, D.J., 2007. Soluble protein oligomers in neurodegeneration: lessons from the Alzheimer's amyloid $\beta$-peptide. Nat. Rev. Mol. Cell Biol. 8, $101-112$.

Herholz, K., Carter, S.F., Jones, M., 2007. Positron emission tomography imaging in dementia. Br. J. Radiol. 80, S160-S167.

Husseman, J.W., Hallows, J.L., Bregman, D.B., Leverenz, J.B., Nochlin, D., Jin, L.W., Vincent, I., 2001. Hyperphosphorylation of RNA polymerase II and reduced neuronal RNA levels precede neurofibrillary tangles in Alzheimer disease. J. Neuropathol. Exp. Neurol. 60, 1219-1232.

Ipata, P.L., Camici, M., Micheli, V., Tozzi, M.G., 2011. Metabolic network of nucleosides in the brain. Curr. Top. Med. Chem. 11, 902-922.

Isobe, C., Abe, T., Terayama, Y., 2010. Levels of reduced and oxidized coenzyme Q-10 and 8-hydroxy-2'-deoxyguanosine in the CSF of patients with Alzheimer's disease demonstrate that mitochondrial oxidative damage and/or oxidative DNA damage contributes to the neurodegenerative process. J. Neurol. 257, 399-404.

Johansson, K., Ramaswamy, S., Ljungcrantz, C., Knecht, W., Piskur, J., MunchPetersen, B., Eriksson, S., Eklund, H., 2001. Structural basis for substrate specificities of cellular deoxyribonucleoside kinases. Nat. Struct. Biol, 8, 616-620.

Jové, M., Portero-Otín, M., Naudi, A., Ferrer, I., Pamplona, R., 2014. Metabolomics of human brain aging and age-related neurodegenerative diseases. J. Neuropathol. Exp. Neurol. 73, 640-657.

Jové, M., Serrano, J.C., Ortega, N., Ayala, V., Anglés, N., Reguant, J., Morelló, J.R., Romero, M.P., Motilva, M.J., Prat, J., Pamplona, R., Portero-Otin, M., 2011. Multicompartmental LC-Q-TOF-based metabonomics as an exploratory tool to identify novel pathways affected by polyphenol-rich diets in mice. J. Proteome Res. 10, 3501-3512.

Jüllig, M., Eriksson, S., 2000. Mitochondrial and submitochondrial localization of human deoxyguanosine kinase. Eur. J. Biochem. 267, 5466-5472.

Kaddurah-Daouk, R., Rozen, S., Matson, W., Han, X., Hulette, C.M., Burke, J.R., Doraiswamy, P.M., Welsh-Bohmer, K.A., 2011. Metabolomic changes in autopsyconfirmed Alzheimer's disease. Alzheimers Dement. 7, 309-317.

Kaddurah-Daouk, R., Zhu, H., Sharma, S., Bogdanov, M., Rozen, S.G., Matson, W. Oki, N.O., Motsinger-Reif, A.A., Churchill, E., Lei, Z., Appleby, D., Kling, M.A., Trojanowski, J.Q., Doraiswamy, P.M., Arnold, S.E., Pharmacometabolomics Research Network, 2013. Alterations in metabolic pathways and networks in Alzheimer's disease. Transl. Psychiatry 3, e244.

Kanehisa, M., Goto, S., 2000. KEGG: kyoto encyclopedia of genes and genomes. Nucleic Acids Res. 28, 27-30.

Kang, T.H., Guibinga, G.H., Jinnah, H.A., Friedmann, T., 2011. HPRT deficiency coordinately dysregulates canonical Wnt and presenilin-1 signaling: a neurodevelopmental regulatory role for a housekeeping gene? PLoS One 6, e16572.

Kim, S.H., Fountoulakis, M., Cairns, N.J., Lubec, G., 2002. Human brain nucleoside diphosphate kinase activity is decreased in Alzheimer's disease and Down syndrome. Biochem. Biophys. Res. Commun. 296, 970-975.

Lee, J.H., Yu, W.H., Kumar, A., Lee, S., Mohan, P.S., Peterhoff, C.M., Wolfe, D.M., Martinez-Vicente, M., Massey, A.C., Sovak, G., Uchiyama, Y., Westaway, D., Cuervo, A.M., Nixon, R.A., 2010. Lysosomal proteolysis and autophagy require presenilin 1 and are disrupted by Alzheimer-related PS1 mutations. Cell 141, 1146-1158.

Li, K., Müller, I., Patil, S., Höger, H., Pollak, A., Russo-Schlaff, N., Lubec, G., Li, L., 2012. Strain-independent global effect of hippocampal proteins in mice trained in the Morris water maze. Amino Acids 43, 1739-1749.

Liauw, J., Nguyen, V., Huang, J., St George-Hyslop, P., Rozmahel, R., 2002. Differential display analysis of presenilin 1-deficient mouse brains. Brain Res. Mol. Brain Res. 109, 56-62.
Loh, S.H., Francescut, L., Lingor, P., Bähr, M., Nicotera, P., 2008. Identification of new kinase clusters required for neurite outgrowth and retraction by a loss-of function RNA interference screen. Cell Death Differ. 15, 283-298.

Lovell, M.A., Markesbery, W.R., 2008. Oxidatively modified RNA in mild cognitive impairment. Neurobiol. Dis. 29, 169-175.

Lovell, M.A., Soman, S., Bradley, M.A., 2011. Oxidatively modified nucleic acids in preclinical Alzheimer's disease (PCAD) brain. Mech. Ageing Dev. 132, 443-448.

Lowe, J., Mirra, S.S., Hyman, B., Dickson, D.W., 2008. 'Ageing and dementia'. In: Love, S., Louis, D.N., Ellison, D.W. (Eds.), Greenfield's neuropathology, vol. 1. Hodder Arnold, London.

Mandel, H., Szargel, R., Labay, V., Elpeleg, O., Saada, A., Shalata, A., Anbinder, Y. Berkowitz, D., Hartman, C., Barak, M., Eriksson, S., Cohen, N., 2001. The deoxyguanosine kinase gene is mutated in individuals with depleted hepatocerebral mitochondrial DNA. Nat. Genet. 29, 337-341.

Markesbery, W.R., Lovell, M.A., 2006. DNA oxidation in Alzheimer's disease. Antioxid. Redox Signal 8, 2039-2045.

Noma, T., 2005. Dynamic of nucleotide metabolism as a supporter of life phenomena. J. Med. Invest. 5, 127-136.

Nunomura, A., Tamaoki, T., Motohashi, N., Nakamura, M., McKeel Jr., D.W. Tabaton, M., Lee, H.G., Smith, M.A., Perry, G., Zhu, X., 2012. The earliest stage of cognitive impairment in transition from normal aging to Alzheimer disease is marked by prominent RNA oxidation in vulnerable neurons. J. Neuropathol. Exp. Neurol. 71, 233-241.

Qureshi, H.Y., Li, T., MacDonald, R., Cho, C.M., Leclerc, N., Paudel, H.K, 2013. Interaction of $14-3-3 \zeta$ with microtubule-associated protein tau within Alzheimer's disease neurofibrillary tangles. Biochemistry 52, 6445-6455.

Rahman, A., 2009. The role of adenosine in Alzheimer's disease. Curr. Neuropharmacol. 7, 207-216

Ribeiro, J.A., Sebastião, A.M., Mendonça, A., 2003. Adenosine receptors in the nervous system: pathophysiological implications. Prog. Neurobiol. 68, 377-392.

Robles, M.S., Cox, J., Mann, M., 2014. In-vivo quantitative proteomics reveals a key contribution of post-transcriptional mechanisms to the circadian regulation of liver metabolism. PLoS Genet. 10, e1004047.

Ronchi, D., Garone, C., Bordoni, A., Gutierrez Rios, P., Calvo, S.E., Ripolone, M., Ranieri, M., Rizzuti, M., Villa, L., Magri, F., Corti, S., Bresolin, N., Mootha, V.K., Moggio, M., DiMauro, S., Comi, G.P., Sciacco, M., 2012. Next-generation sequencing reveals DGUOK mutations in adult patients with mitochondrial DNA multiple deletions. Brain 135, 3404-3415.

Sana, T.R., Roark, J.C., Li, X., Waddell, K., Fischer, S.M., 2008. Molecular formula and METLIN personal metabolite database matching applied to the identification of compounds generated by LC/TOF-MS. J. Biomol. Tech. 19, 258-266.

Smyth, G.K., 2005. Limma: linear models for microarray data. In: Gentleman, R. Carey, V., Dudoit, S., Irizarry, R., Huber, W. (Eds.), Bioinformatics and Computational Biology Solutions Using R and Bioconductor. Springer, New York, pp. 397-420.

Tsai, I.L., Kuo, T.C., Ho, T.J., Harn, Y.C. Wang, S.Y., Fu, W.M., Kuo, C.H., Tseng, Y.J., 2013. Metabolomic dynamic analysis of hypoxia in MDA-MB-231 and the comparison with inferred metabolites from transcriptomics data. Cancers (Basel) 5, 491-510.

Tumini, E., Porcellini, E., Chiappelli, M. Conti, C.M., Beraudi, A., Poli, A., Caciagli, F. Doyle, R., Conti, P., Licastro, F., 2007. The G51S purine nucleoside phosphorylase polymorphism is associated with cognitive decline in Alzheimer's disease patients. Hum. Psychopharmacol. 22, 75-80.

Ulas, J., Brunner, L.C., Nguyen, L., Cotman, C.W., 1993. Reduced density of adenosine A1 receptors and preserved coupling of adenosine A1 receptors to G proteins in Alzheimer hippocampus: a quantitative autoradiographic study. Neuroscience 52, 843-854.

Weidner, A.M., Bradley, M.A., Beckett, T.L., Niedowicz, D.M., Dowling, A.L. Matveev, S.V., LeVine 3rd, H., Lovell, M.A., Murphy, M.P., 2011. RNA oxidation adducts 8-OHG and 8-OHA change with Aß42 levels in late-stage Alzheimer's disease. PLoS One 6, e24930.

Xia, J., Mandal, R., Sinelnikov, I., Broadhurst, D., Wishart, D.S., 2012. MetaboAnalyst 2.0-a comprehensive server for metabolomic data analysis. Nucl. Acids Res. 40 (Web Server issue), W127-W133.

Yegutkin, G.G., 2008. Nucleotide- and nucleoside-converting ectoenzymes: important modulators of purinergic signalling cascade. Biochim. Biophys. Acta 1783 673-694. 